\title{
Characteristic sizes of life in the oceans - from bacteria to whales
}

Andersen, Ken Haste; Berge, T.; Goncalves, R.; Hartvig, Martin; Heuschele, Jan; Hylander, Samuel; Jacobsen, Nis Sand; Lindemann, Christian; Martens, Erik Andreas; Neuheimer, Anna

Total number of authors:

18

Published in:

Annual Review of Marine Science

Link to article, DOI:

10.1146/annurev-marine-122414-034144

Publication date:

2016

Document Version

Peer reviewed version

Link back to DTU Orbit

Citation $(A P A)$ :

Andersen, K. H., Berge, T., Goncalves, R., Hartvig, M., Heuschele, J., Hylander, S., Jacobsen, N. S., Lindemann, C., Martens, E. A., Neuheimer, A., Olsson, K., Palacz, A., Prowe, F., Sainmont, J., Traving, S. J. Visser, A., Wadhwa, N., \& Kiørboe, T. (2016). Characteristic sizes of life in the oceans - from bacteria to whales. Annual Review of Marine Science, 8(3), 217-241. https://doi.org/10.1146/annurev-marine-122414-034144

\section{General rights}

Copyright and moral rights for the publications made accessible in the public portal are retained by the authors and/or other copyright owners and it is a condition of accessing publications that users recognise and abide by the legal requirements associated with these rights.

- Users may download and print one copy of any publication from the public portal for the purpose of private study or research.

- You may not further distribute the material or use it for any profit-making activity or commercial gain

- You may freely distribute the URL identifying the publication in the public portal 


\section{Characteristic sizes of life in the oceans, from bacteria to}

\section{2 whales}

3 Running title: Characteristic sizes of life in the oceans

4

5 K.H. Andersen, T. Berge, R. J. Gonçalves, M. Hartvig, J. Heuschele, S. Hylander, N.S.

6 Jacobsen, C. Lindemann, E.A. Martens, A.B. Neuheimer, K. Olsson, A. Palacz, F.

7 Prowe, J. Sainmont, S.J. Traving, A.W. Visser, N. Wadhwa, and T. Kiørboe

8

9

10 K.H. Andersen¹,2: kha@aqua.dtu.dk. Corresponding author, tel. +45 35883399.

11 T. Berge ${ }^{1,8}:$ tberge@bio.ku.dk

12 R. J. Gonçalves ${ }^{1,2,10}$ : rgon@aqua.dtu.dk

13 M. Hartvig2,3,4: mh@hvig.dk

14 J. Heuschele ${ }^{1,2}$ : janheuschele@gmail.com

15 S. Hylander ${ }^{2,9}$ : samuel.hylander@lnu.se

16 N.S. Jacobsen¹,2: nsja@aqua.dtu.dk

17 C. Lindemann" ${ }^{1,2}$ : chrli@aqua.dtu.dk

18 E.A. Martens ${ }^{1,2,7}$ : erik.martens@ds.mpg.de

19 A.B. Neuheimer 2,3,6: annabn@hawaii.edu

20 K. Olsson ${ }^{1,2}$ : karol@aqua.dtu.dk

21 A. Palacz ${ }^{1,2}$ : arpa@aqua.dtu.dk

22 F. Prowe ${ }^{1,2,11}$ : fprowe@geomar.de

23 J. Sainmont ${ }^{1,2}$ : jusa@aqua.dtu.dk 
A.W.Visser ${ }^{1,2}$ : awv@aqua.dtu.dk

N. Wadhwa1,5: nawa@fysik.dtu.dk

27 T. Kiørboe ${ }^{1,2}:$ tk@aqua.dtu.dk

1: VKR Centre for Ocean Life.

2: National Institute of Aquatic Resources, Technical University of Denmark,

3: Center for Macroecology, Evolution and Climate, Natural History Museum of

Denmark, University of Copenhagen, Universitetsparken 15, 2100 Copenhagen,

Denmark

4: Systemic Conservation Biology, J.F. Blumenbach Institute of Zoology and Anthropology, University of Göttingen, Berliner Strasse 28, 37073 Göttingen,

5: Department of Physics, Technical University of Denmark

6: Department of Oceanography, University of Hawai'i at Mānoa, 1000 Pope

41 7: Department of Biomedical Sciences, Copenhagen University, Blegdamsvej 3, 2200 Copenhagen, Denmark

8: Marine Biological Section, University of Copenhagen, Strandpromenaden 5,

443000 Helsingør, Denmark

45 9: Faculty of Health and Life Sciences, Linnaeus University, Kalmar, Sweden

46 10: Consejo Nacional de Investigaciones Científicas y Técnicas, Argentina 
47 11: GEOMAR Helmholtz Centre for Ocean Research Kiel, Wischhofstr. 1-3,

4824148 Kiel, Germany 
61 Keywords: body size, metabolism, allometric scaling, plankton, mixotrophy, fish,

62 whales

63

64 The size of an individual organism is a key trait to characterize its physiology

65 and feeding ecology. Size-based scaling laws may have a limited size range of

66 validity or undergo a transition from one scaling exponent to another at some

67 characteristic size. We collate and review data on size-based scaling laws for

68 resource acquisition, mobility, sensory range and progeny size for all pelagic

69 marine life, from bacteria to whales. Further, we review and develop simple

70 theoretical arguments for observed scaling laws and the characteristic sizes of a 
71 change or breakdown of power laws. We divide life in the ocean into seven major

72 realms based on their trophic strategy, physiology and life history strategy. Such

73 a categorization represents a move away from a taxonomically oriented

74 description towards a trait-based description of life in the oceans. Finally, we

75 discuss life forms that transgress the simple size-based rules and identify

76 unanswered questions.

77

$78 \quad$ Number of words in abstract: 149

79 Number of words in text: 7500

$80 \quad$ Number of words in Sidebar 1: 542

$81 \quad$ Number of words in Sidebar 2:375

$82 \quad$ Number of references: 93 (limit 100).

83 Number of figures, tables and text-boxes: 7, 1, 2 (limit 10)

84 Online appendices: 4. 


\section{Introduction}

Since the essay by Haldane (1928) "On being the right size" biologists have used organism size as a master trait to characterize the capabilities and limitations of individual organisms. There are good reasons for doing so. It is evident that the physiology and ecology of a copepod and a dolphin are vastly different, much more so than the difference between a copepod and a fish larva. Organism size describes individual physiology across major taxa through power-law functions (Peters 1983): metabolism, leading to the celebrated 3/4 law for the scaling of resting metabolism with size (Hemmingsen 1960, Kleiber 1932, West et al. 1997, Winberg 1956), population growth rates (Fenchel 1974, Gillooly et al. 2002), predator-prey relationships in terms of functional response (Hansen et al. 1997;

Kiørboe 2011; Rall et al. 2012) and predator-prey ratios (Barnes et al. 2008, Cohen et al. 1993, Hansen et al. 1994), fluid-mechanical forces (Bejan \& Marden 2006), swimming speed (Ware 1978; Kiørboe 2011), vision (Dunbrack \& Ware 1987), diffusive uptake affinities (Aksnes \& Egge 1991, Berg \& Purcell 1977, Edwards et al. 2012, Litchman et al. 2007, Munk \& Riley 1952, Tambi et al. 2009) and, for phytoplankton, affinities for light (Finkel 2001, Taguchi 1976) and maximum uptake rates (Edwards et al. 2012, Marañón et al. 2013). Size has also been used to describe macro-ecological patterns of size-dependent species diversity (Fenchel \& Finlay 2004, May 1975, Reuman et al. 2014), and the biomass distribution of individuals as a function of size across major taxa (Boudreau \& Dickie 1992, Sheldon \& Prakash 1972) has been explained theoretically using the size relationships describing individual physiology (Sheldon et al. 1977; Andersen \& Beyer 2006). While developing these size- 
based relations the focus has been on determining the exponent (the "slope")

110 and the constant ("intercept"), with less attention being paid to the sizes that

111 limits the range of their validity.

113 On closer inspection, some power-laws relationships are seen to change scaling

114 exponent and/or intercept around some particular size or even break down

115 altogether beyond a range of validity. The fluid flow around a whale, for example,

116 is turbulent leading to dominance of inertial forces with a drag force scaling with

117 the length and velocity squared. In contrast, the flow around a unicellular

118 organism is laminar and dominated by viscous forces with a drag force scaling

119 linearly with velocity and length. Consequently, the scaling of drag force changes

120 at the organism size where there is a transition between viscous and turbulent

121 flow. As example of a breakdown, consider the visual range. The larger the eye,

122 the longer an organism can see. However, there is an upper visual range

123 determined by the sensitivity of the retina (Dunbrack \& Ware 1987), as well as a

124 lower limit of eye size determined by the size of the visual elements in the retina

125 and the wavelength of light. The scaling law for visual range is therefore valid

126 only within the upper and lower limits. Such changes or breakdowns in scaling

127 laws have consequences for adaptations and strategies of marine organisms. For

128 example, predators so large that they are in the inertial fluid regime develop a

129 streamlined body shape for efficient swimming and predators smaller than the

130 lower size of an eye cannot rely on vision. 

convenient size, and a large change in size inevitably carries with it a change of

134 form". Our aim is to determine the sizes where scaling relationships change or

135 break down and to use those characteristic sizes to explain the fundamental 136 differences in the form and function of marine organisms with different sizes. To 137 this end we build on the large existing literature of empirical size-based scaling 138 relations and their theoretic explanations.

140 We categorize pelagic life in the ocean based on size in seven general realms:

141 molecular life (viruses), osmo-heterotrophic bacteria, unicellular phototrophs, 142 unicellular mixotrophs and heterotrophs, planktonic multi-cellular heterotrophs 143 (e.g. copepods), visually foraging poikilotherms (e.g. fish), and homeothermic 144 animals (whales). This categorization of life is a deliberately crude 145 representation of the roughly 200,000 eukaryotic species, plus an unknown 146 number of archea and bacteria, in the ocean (May \& Godfrey 1994), as it is 147 explicitly designed to facilitate an understanding based on size. We describe the 148 life forms in each realm according to their body size and determine characteristic 149 sizes where there is a transition from one realm to another. In this manner we 150 emphasize body size as a fundamental driver of macro-ecological patterns in the 151 oceans.

153 We examine five aspects of life where size is a dominant driver: (i) resource 154 encounter through predation, diffusive uptake or photosynthesis, (ii) mobility, 155 (iii) sensing through chemical and hydromechanical signals, vision, and 
echolocation, (iv) life history strategy in terms of adult and progeny sizes and (v)

157 body temperature (

158 Figure 1). To this end we draw on a wide range of theories: diffusion theory, fluid

159 mechanics, optics, metabolic theory, and optimal life history theory. We review

160 established theoretical and empirical scaling laws and establish characteristic

161 sizes where the scaling laws change or break down. These characteristic sizes

162 are used to formulate hypotheses about the dominant strategy for organisms of a

163 given size within the five aspects, e.g. how an organism obtains carbon (through

164 photosynthetic assimilation of inorganic carbon, from dissolved organic matter,

165 or from particulate organic matter), or which senses it employs for prey

166 encounter. We test the hypotheses by collecting data on strategies of individuals

167 as a function of their size. Since our arguments are general in nature they apply

168 largely to all aquatic life but our focus is pelagic marine life. The final synthesis is

169 a description of the dominant forms and functions of life in the oceans. This is

170 used to frame a discussion of strategies and life forms that transcends the

171 general size-based patterns and to point towards open unanswered questions.

\section{What is 'size'?}

173 The size of an organism can be characterized by its length or by its weight. Wet

174 weight, dry weight and carbon weight are the most common weight measures,

175 while length is typically measured as the largest linear dimension or the

176 equivalent spherical diameter (ESD). Depending on the question one measure

177 may be more appropriate than the other. For example the flow around an

178 organism is determined by its linear size and shape, not by its weight.

179 Conversely, the bioenergetic budget of an organism is adequately described in 
terms of weight since the energetic budget should reflect a conservation of mass.

181 For microbes weight is often measured in carbon or in units of the limiting

182 nutrients since water content and ratios between fundamental elements vary

183 between organisms (Klausmeier et al. 2004). The elemental ratios and water

184 content of vertebrates vary less than they do for invertebrates so wet weight is

185 often preferred as an intuitive measure of weight for vertebrates. Even though it

186 would be possible, we do not find it useful to convert all sizes to a common

187 measure and consequently use the most convenient measure depending on the

188 situation. We will use the symbols $w$ for a weight and $l$ for length, $d$ for diameter

189 and $r$ for radius and frequently make use of the conversion between length and

190 weight as $w \propto l^{3}$. Units of weight are indicated with subscripts: $\mathrm{g}_{W w}, \mathrm{~g}_{C}$,

191 referring to wet weight and carbon weight. Conversion relations are provided in

192 Table S1.1.

\section{Resource acquisition and trophic strategies}

194 Organisms acquire carbon and nutrients through feeding on encountered

195 resources. "Resources" is here understood broadly as dissolved inorganic

196 nutrients, dissolved organic molecules, photons or prey organisms. The

197 encounter with resources occurs by three mechanisms: 1) active encounter

198 through cruising, ambushing or creation of a feeding current, 2) fixation of

199 carbon through photosynthesis or, 3) passive encounter with food items which

200 diffuse towards the feeding individual. The encounter rate (biomass per time) is

201 described as:

202 


$$
E=\beta C
$$

203

204 where $\beta$ is the clearance rate (volume per time) and $C$ the resource

205 concentration (biomass per volume). In terms of a type II functional response

206 (Holling 1959) the clearance rate is the slope at the origin i.e., the potential

207 volume of water cleared for resources per unit time when uptake is not limited

208 by handling time or physiological limits (digestion). These limitations are not

209 considered here. The clearance rate is described as a power function of size

$210 \beta=b l^{a}$. We employ the linear dimension $l$ to characterize size because resource

211 uptake is determined by the physical size of an organism, not by its weight. In the

212 following we describe how the exponent $a$ and the factor $b$ depends on size for

213 the three different resource acquisition mechanisms on the basis of physical

214 processes and empirical cross-species relationships. This analysis allows us to

215 characterize the dominant trophic strategy of organisms, e.g. phototrophs or

216 heterotrophs, as a function of their size and the biotic and abiotic environment.

218 Active predation

219 Large protozoans and metazoans have three fundamental modes of actively

220 encountering prey: ambushing, generating a feeding current or cruising through

221 the water searching for prey (Kiørboe, 2011). The clearance rate of each mode

$222 \beta_{A}$ can be estimated as a velocity multiplied by an encounter cross section. A

223 planktonic filter-feeder, for example, captures prey on its filter with a size scaling

224 as the length of the organism squared $l^{2}$, with a feeding-current velocity $u \approx l^{0.8}$

225 (Huntley \& Zhou 2004) leading to a scaling exponent of the clearance rate of 
$a_{A} \approx 2.8$. Using similar arguments for the other feeding modes all lead to exponents $\approx 2.8$, i.e. slightly below 3 , but multiplied by different factors (Kiørboe

228 2011). Since one feeding mode replaces the other depending on environmental

229 conditions and the size of the prey and the predator, the average life-form-

230 transcending scaling exponent becomes around 3 (

231 Figure 2a; Table S1.2):

232

$$
\beta_{A}=b_{A} l^{3}
$$

233

234 Weight-specific uptakes rates, $\propto \beta_{A} / w$, are therefore independent of size since $235 w \propto l^{3}$ (Kiørboe \& Hirst 2014).

236

237 Photosynthesis

238 Fixation of dissolved $\mathrm{CO}_{2}$ by photosynthesis requires encounter with photons

239 (we assume that $\mathrm{CO}_{2}$ is not limiting). Photosynthesis can in principle occur

240 throughout the cell but for larger cells it is limited by self-shading of photons

241 (the "package effect") (Morel \& Bricaud 1981). For the present arguments, it is

242 sufficient to consider that the cross-sectional area of the cell $\propto l^{2}$ limits

243 photosynthesis (

244 Figure 2b):

245

$$
\beta_{L}=b_{L} l^{2} \text { (2). }
$$


247 The clearance rate $\beta_{L}$ is often termed light affinity or photosynthetic efficiency

248 and is measured in dimensions of carbon fixed per photon multiplied by area. In

249 terms of weight specific scaling, the power 2 scaling of $\beta_{L}$ results in a scaling of

250 weight specific rates of carbon fixation $\beta_{L} / w \propto w^{-1 / 3}$, i.e. smaller organisms

251 have a higher specific rate of carbon fixation than larger ones. Organisms smaller

252 than a certain size are therefore able to fix more carbon by photosynthesis than

253 by active encounter since specific uptake by active encounter is independent of

254 size.

Diffusion feeding

257 Organisms that encounter resource items as they bump into the surface of the 258 organism due to Brownian motion are termed "diffusion feeding" (Fenchel 259 1984). Diffusion feeding is used to assimilate dissolved organic molecules, 260 inorganic carbon and nutrients. The uptake rate is limited by the number of 261 uptake sites on the surface of the cell, which can be expected to scale with $l^{2}$. 262 However, the uptake also removes resources from the vicinity of the cell surface 263 and creates a boundary layer of lower resource concentrations near the cell than 264 far away (Munk \& Riley 1952). This effectively leads to the clearance rate $265 \beta_{D}$ being limited rather by diffusion than by the surface, with a scaling 266 proportional to the linear dimension of the cell (reviewed by Fiksen et al. 2013):

$$
\beta_{D}=b_{D} l^{1}(3)
$$


270 Weight specific uptake rates are then $\propto w^{-2 / 3}$, i.e., high for small cells and

271 declining with size. Small diffusion feeding cells therefore have a higher

272 encounter rate with dissolved nutrients or macromolecules than they could have

273 obtained by active feeding. The theoretic scaling prediction fits with data for

274 phosphate affinity (

275 Figure 2c). Data for nitrogen affinity are less clear, with some being consistent

276 with the theoretic scaling $\left(a_{D}=1.2\right)$ (Litchman et al. 2007) and others not

$277 \quad\left(a_{D}=2.25\right)($ Edwards et al. 2012).

278

279 Trophic strategies

280 An organism's trophic strategy, i.e., which type of food it consumes, is to a large

281 degree determined by its resource acquisition mechanism. It can be an osmo-

282 heterotroph that diffusion feeds on dissolved organic matter (bacteria), a

283 phototroph that captures light and diffusion feeds on dissolved inorganic

284 nutrients (phytoplankton), a mixotroph that captures light and feeds on other

285 organisms, or an actively feeding heterotroph (animals and many protists). If we

286 use clearance rate as a proxy for competitive ability at low resource

287 concentrations, we can assume that the dominant trophic strategy of organisms

288 at a given size is determined by the resource acquisition mechanism yielding the

289 highest encounter rate. The encounter rates for the four trophic strategies as a

290 function of size is given by Eq. 1 where the resource may be either

291 concentrations of dissolved organic molecules $C_{\mathrm{DOM}}$, nutrients $C_{N}$, other prey

292 organisms $C_{P}$, or the light flux $C_{L}$. Phototrophs need special treatment since they

293 assimilate inorganic carbon and nutrients by two different processes. Carbon is 
assimilated through photosynthesis and combined with diffusively encountered nutrients to achieve a $\mathrm{C} / \mathrm{N}$ ratio $c_{\mathrm{CN}}$. The limiting compound determines encounter as described by Liebig's law of the minima:

297

$$
E=\min \left\{c_{\mathrm{CN}} \cdot \beta_{D} \cdot C_{N}, \quad \beta_{L} \cdot C_{L}\right\}
$$

299 For a particular environment of light, nutrients, organic matter and prey, an 300 organism encounters different specific amounts of resources from the various 301 encounter mechanisms (

302 Figure 3). The smallest organisms get the highest encounter rate from diffusive 303 encounter with dissolved organic matter. Diffusion feeding heterotrophic 304 bacteria (osmo-heterotrophs) will therefore dominate among the smallest 305 organisms. As size increases, encounter with photons becomes sufficiently high 306 to make photosynthesis combined with diffusive uptake of inorganic nutrients 307 optimal, i.e., the dominant strategy becomes phototrophy. The transition size is 308 when carbon fixation by photosynthesis $\beta_{L} C_{L}=b_{L} l^{2} C_{L}$ becomes equal to the 309 diffusive encounter with dissolved organic matter $\beta_{D} C_{\mathrm{DOM}}=b_{D} l C_{\mathrm{DOM}}$, which 310 occurs at a size:

$$
l=\frac{C_{D O M} b_{D}}{C_{L} b_{L}} .
$$

312 Cells larger than this size are expected to be light-limited phototrophs. When the 313 cells reach a size 


$$
l=\frac{c_{C N} C_{N} b_{D}}{C_{L} b_{L}}
$$

316 the diffusive uptake of inorganic nutrients becomes limiting (Mei et al. 2009).

317 Larger cells will still benefit from acquisition of carbon through the aid of

318 photosynthesis but they will be nutrient limited. At a size

$$
l=\frac{c_{C N} C_{N} b_{D}}{C_{F} b_{A}}
$$

321 active encounter with prey organisms provides the highest encounter rates, i.e.,

322 heterotrophic animals. There is a particular range where photosynthesis will

323 provide more carbon than active encounter (predation) but where active

324 encounter provides more nutrients than diffusive uptake of inorganic nutrients.

325 In this size-range a mixotrophic strategy is profitable, i.e. using photosynthesis,

326 either from ingested or own chloroplast, predominantly to provide carbon for

327 metabolism, and using active feeding to assimilate nutrients and carbon for

328 biomass synthesis (mixotrophs of type II and III; Stoecker, 1998).

330 The size range where a certain trophic strategy gives the highest yield depends

331 on the concentration of available resources. If, for example, the concentration of

332 prey organisms is increased, the lower size limit where active feeding gives the

333 highest yield is decreased. The transition size between the dominant feeding

334 strategies will therefore be different under oligotrophic conditions (high light

335 and low nutrient concentrations, such as summer surface conditions in seasonal 
environments or oceanic regions) than under eutrophic conditions (low light and

337 high nutrient concentrations, such as spring surface conditions in seasonal

338 environments or conditions at depth) (Figure $4 \mathrm{a}+\mathrm{b})$. The general pattern of small

339 diffusion feeders, medium phototrophs, and large active feeders is identical

340 between oligotrophic and eutrophic environments, but the sizes where the

341 transitions occur vary: oligotrophic conditions give rise to smaller phototrophs

342 and a large size-range of mixotrophs, while eutrophic situations conditions lead

343 to larger osmo-heterotrophic bacteria, phototrophs and mixotrophs. The general

344 pattern fits well with the classical interpretation of the seasonal succession of

345 cell size in temperate systems (Kiørboe, 1993): large (diatoms) cells dominate

346 during nutrient rich spring conditions but are overtaken by smaller cells

347 (dinoflagellates and cryptophytes), often with a mixotrophic strategy during the

348 nutrient depleted summer conditions (Barton et al. 2013).

350 A compilation of the dominant trophic strategies according to size largely

351 confirms the theoretical predictions while also highlighting the large overlap in

352 the size-range between phototrophs, mixotrophs and small heterotrophs (

353 Figure 4c). The overlap reflects that the compilation is based on the observations

354 from various environmental conditions that, as demonstrated above, create a

355 significant variation in the transition sizes where one trophic strategy gives a

356 higher yield than another strategy.

\section{Mobility}

358 Movement is powered by muscles or flagellae and constrained by friction from

359 the water. From an organism's perspective the nature of the water changes 
dramatically with size: large organisms use their inertia to coast through the

361 water while smaller organisms experience water as thick and sticky. Very small

362 organisms have to cope with the random forces of molecules that induce

363 Brownian motion (Dusenbery 2009). The hydromechanics of movement can

364 therefore be divided into three regimes: an inertial regime, a viscous regime and

365 a Brownian regime. Here we are mainly concerned with the difference between

366 the inertial and viscous regimes. The hydrodynamic regime determines the

367 forces upon the body, which in turn influences the optimal shape. In the viscous

368 regime the dominating force is surface friction, which scales with the linear

369 dimensions of the body. In the viscous regime it is therefore optimal to reduce

370 the surface area, i.e. to be spherical (actually, the optimal shape is deviating

371 slightly from spherical; Dusenbery, 2009). In the inertial regime the drag force is

372 proportional to the projected frontal area of the organisms making it optimal to

373 reduce this area by streamlining..

375 Whether an organism is in the inertial or viscous regime depends on the

376 Reynolds number $R e=u l / v$ that describes the ratio between inertial and

377 viscous forces operating on a body of size $l$ moving at velocity $u$ through water

378 with kinematic viscosity $v \approx 10^{-2} \mathrm{~cm}^{2} / \mathrm{s}$. The crossover between the two

379 regimes is at $R e \approx 20-30$ (Webb 1988). The scaling of swimming velocity with

380 size in the two regimes differs: in the viscous regime the velocity was found

381 empirically to scale as $l^{0.79}$ (Kiørboe, 2011) while in the inertial regime theoretic 382 arguments predict a length scaling with exponents 0.42 (Ware 1978) or 0.5

383 (Bejan \& Marden 2006); observation suggest a scaling $u \propto l^{0.45}$ (Figure 5a). The 
empirical data indicate a crossover size between the viscous and inertial regime at body length of around $7 \mathrm{~cm}$ corresponding to a Reynolds number on the order of 1000. The relevance of size for body shape is evident (Figure 5b): small organisms do not appear constrained on their body shape, while fish and mammals are streamlined with an average aspect ratio around 0.25 . Copepods are in between; they have a significantly larger aspect ratio than fish. During

390 jumps, however, the Reynolds number becomes large thus giving them the 391 advantage of a relatively slender body plan (Kiørboe et al. 2010).

\section{Size and sensing}

393 Actively feeding organisms perceive their prey by chemical or hydromechanical 394 cues, vision, or echolocation. The range of sensing is determined by the size of 395 the predator and the prey; a blue whale with an eye diameter of $15 \mathrm{~cm}$ sees 396 much further than a fish larva with an eye diameter of $1 \mathrm{~mm}$. The sense with the 397 furthest range for organisms of a given size can be expected to dominate among 398 organisms of that size. Organisms using more than one sense complicate the 399 analysis of senses. For example, sharks use smell to follow the trail of a prey at 400 great distances. When closing in on the prey, vision becomes important (Hueter 401 et al. 2004). At distances below one meter they use electro-sensing for the 402 precise localization of their prey (Collin \& Whitehead 2004). Copepods are 403 generally considered mechanosensing organisms, yet they can sense and follow 404 the chemical trail of a settling marine snow particle (Kiørboe 2001) or the 405 pheromone trail of a potential mate (Bagøien \& Kiørboe 2005). Leaving such 406 complications aside we nevertheless proceed to review estimates of the sensory 
range of four senses where the sensing range depend on the size of the predator: chemical sensing, sensing of hydromechanical signals, vision and echolocation.

Chemosensing

411 In that all organisms depend on chemistry in one way or another, it may be

412 safely assumed that they have machinery for chemical sensing. The question is

413 how chemosensing together with behavior can bring organisms into contact with

414 remote resources. The way organism's experience the coherence of chemical

415 gradients and trails is determined by individual size in relation to turbulent

416 eddies. Turbulence is characterized by three length scales (Tennekes \& Lumley

417 1972): the Batchelor scale, $\approx 10 \mu \mathrm{m}$ in the upper ocean, where turbulence starts

418 to erode the regularity of a gradient, the Kolmogorov scale $\approx 1000 \mu$ m where

419 turbulence starts to impede the organism's ability to maintain direction, and the

420 integral scale $\approx 1-10 \mathrm{~m}$ where turbulent energy is injected by large-scale

421 motions.

423 We distinguish between two modes of chemosensing: gradient climbing (e.g.

424 bacterial run-tumble) and trail following (e.g. a shark following a prey trail).

425 Gradient climbing relies on a chemical gradient set up by molecular diffusion of a 426 solute from a source. The regularity of such gradients would be scale

427 independent if it were not for turbulence. We can place an upper boundary for

428 gradient climbing at between the Batchelor scale and the Kolmogorov scale, in 429 the range from $10-1000 \mu \mathrm{m}$. Another limitation of the ability to follow gradients 430 created by molecular diffusion is whether the trail is diffusing faster than the 
431 movement of the prey. This criterion sets an upper limit for predator size of 50

$432 \mu \mathrm{m}$ (Kiørboe 2011). For trail following, additional criteria come into effect: the

433 movement of the target organism, the rate at which it releases solute and how

434 well the searching organism can detect this solute above background levels. In

435 any case, organisms smaller than the energy containing turbulent eddies will

436 experience the trail as patchy and therefore need to search large areas relative to

437 their own size to follow the trail. This scenario is relevant for organisms of a size

438 between the Kolmogorov and the integral length scales, i.e. organisms smaller

439 than $1 \mathrm{~m}$. Organisms larger than the integral scale are able to integrate over the

440 subscale trail details and follow a trail without detours. Trail following is

441 therefore most advantageous for large organisms and/or quiescent

442 environments, e.g. the deep oceans (Martens et al.).

$444 \quad$ Mechanosensing

445 Ambush feeders may sense their prey via the fluid mechanical disturbance

446 created by a moving prey (reviewed by Kiørboe 2011). To enhance the sensory

447 range they employ special sensory arrangements protruding from the body, like

448 the long setae-studded antennules on copepods or the sensory hairs arranged

449 along the slender body of chaetognaths (arrow worms). The fluid mechanical

450 disturbance of a self propelling prey can be modelled as a stress-let which

451 implies that the signal attenuates as the cube of the distance away from the prey

452 (Visser 2001). The range that this signal can be sensed is

$453 R \approx\left(3 l_{\text {prey }}^{2} l_{\text {sensor }} u_{\text {prey }} / u^{*}\right)^{1 / 3}$ where $u^{*}$ is the detection limit of the velocity

454 disturbance and $l_{\text {sensor }}$ is the length of the sensor, approximately the size of the 
455 predator. Using $u_{\text {prey }}=b l_{\text {prey }}^{0.74}$ and a predator-prey length ratio $B \approx 10$ the

456 sensing distance is $R \approx c l^{1.24}$ with $c \approx 1.4 \mathrm{~cm}^{-0.24}$ for $u^{*}=33 \mu \mathrm{m} / \mathrm{s}$ (Kiørboe

457 2011)(

458 Figure 6). An upper range comes into effect when the turbulent shear $\gamma$ across

459 the body of the predator organism approaches the sensitivity; i.e. when $u^{*}=\gamma l$.

460 For moderate turbulent shears found in the upper ocean $\left(0.03 \mathrm{~s}^{-1}\right.$ which in the

461 middle of the typical range of $10^{-4}-10^{-1} \mathrm{~s}^{-1}$; Visser \& Jackson 2004), this happens

462 for $l$ in the range $500-1000 \mu \mathrm{m}$. Mechanosensing is therefore most advantageous

463 for small organisms $(<1 \mathrm{~cm})$ or on short ranges for large organisms.

464

465 Vision

466 Eyes contain photoreceptors that detect light and convert it into neuronal

467 signals. The simple eyes of some microorganisms are only able to detect changes

468 in the ambient light sufficient for detection of diurnal rhythms, orientation

469 towards the surface and nearby movement. Active visual predation requires an

470 eye with sufficient resolution to form an image and preferably also active optical

471 machinery to focus a targeted object. With regards to feeding, the most

472 important property of the eye is the distance at which it can discern a suitable

473 prey.

474

475 [Sidebar 1 near here]

476

477 Dunbrack and Ware (1987) modelled the optical and sensing abilities of a

478 camera eye to estimate the visual range of a predator of length $l$ searching for 
prey with a fixed fraction of the predator size (Sidebar 1). Two important conclusions emerge from their arguments: First, the sensing range scales as $l^{1.75}$ in clear water under high light conditions. Second the maximum range of large organism is limited by the optical properties of the water. Under perfect conditions the range is between 40-70 m (Davies-Colley \& Smith 1995). The range decreases with the ambient light such that at depth, where the inherent contrast is low, visual range is mainly limited by the optical properties of the water.

A lower size limit of a functioning eye is determined by the finite size of the photoreceptor. Photoreceptors' functioning relies on opsin molecules

490 (rhodopsin) stacked in rod cells with a width $d_{\text {rod }} \approx 1 \mu \mathrm{m}$ (Curcio et al. 1990).

491 Taking account of the universality of the opsin design for photoreception, we

492 may consider this length a limiting factor for building eyes. Considering a

493 minimal resolution of, say $100^{2}$ for sufficient image formation, results in a retina

494 size of $d_{r} \approx 0.1 \mathrm{~mm}$. This is about $1 / 10$ of the size of the smallest aquatic

495 organisms with camera eyes: larval fish and cephalopods. Therefore, vision is

496 only a viable sensing mode for organisms in the size range from a few

497 millimetres and up.

\section{Echolocation}

500 Echolocation is an active sensing mode, where the animal emits ultrasonic calls

501 and interprets the environment based upon the echo of these calls. It is common 
for toothed whales (Odontocetes) and while it is also used for orientation, here we focus on echolocation and its role in prey detection.

504

505 We can estimate how the range $R$ of echolocation scales with the size of the

506 animal based on three assumptions: 1) The sensitivity of the ear $P_{0}$ is

507 independent of the size of the animal, 2) the emitted power scales with an

508 exponent $p$ as $\left.P_{e} \propto w^{p} \propto l^{3 p}, 3\right)$ we ignore frequency dependent attenuation of

509 sound in seawater because this attenuation is small compared to the conical

510 spread of the sound wave. In free space the emitted signal spreads as a conic

511 beam resulting in the attenuation of the signal power as $R^{-2}$. The power of the

512 reflected signal is $P_{r} \propto P_{e} l_{\text {prey }}^{2}(2 R)^{-2}$ where $l_{\text {prey }}^{2}$ is the area of the reflecting

513 target and the factor 2 is because the signal attenuates both as it travels towards

514 the target as well as when it returns. Inserting the power of the emitted signal

515 and absorbing the factor 2 in the proportionality constant gives $P_{r} \propto l^{3 p} l_{\text {prey }}^{2} R^{-2}$.

516 The distance where the strength of the returned signal is just at the sensitivity of

517 the ear, i.e. $P_{0}=P_{r}$, scales as $R \propto P_{0}^{-1 / 2} l_{\text {prey }} l^{3 p / 2}$. If the preferred prey size scales

518 with the size of the predator, i.e. $l_{\text {prey }} \propto l$, then:

519

$$
R \propto P_{0}^{-1 / 2} l^{1+3 p / 2}
$$

521 If the power of the emitted sound follows metabolic scaling, $p=3 / 4$ then the

522 exponent becomes 17/8. This argument only provides the scaling of the sensing

523 range; the factor can be found by fitting to data (

524 Figure 6a). 
Size and sense

527 The theoretic arguments outlined above identified three characteristic sizes

528 where one sense becomes more efficient than another: 1) an upper size limit for

529 gradient climbing at a predator size of around $100 \mu \mathrm{m} ; 2$ ) predators larger than

530 that $100 \mu \mathrm{m}$ but smaller than $1 \mathrm{~mm}$ are expected to rely predominantly on

531 hydromechanical sensing, 3) a size where vision becomes viable for a predators

532 of around $1 \mathrm{~cm}$, and 4) a size of around 1 meter or larger where predators are

533 able to realize the upper visible range of up to 80 meter in clear water. An

534 extension of the sensory range beyond this length can only be achieved by trail-

535 following chemical tracers or by echolocation.

536

537 Analysis of body size and senses used by marine organisms reveals that the

538 number of possible senses available to a predator increases with size (

539 Figure 6b). Large organisms typically combine several senses for foraging. The

540 lower size limit of vision around $1 \mathrm{~cm}$ is clearly borne out; this size indeed

541 corresponds to the smallest size of fish and cephalopods larvae. Some large life

542 forms do not use vision to detect prey, most notably the gelatinous zooplankton,

543 even though they are much larger than $1 \mathrm{~cm}$. Seen in this perspective, the

544 strategy of gelatinous zooplankton is to avoid building a vertebrate body with its

545 associated high metabolic requirements to utilize the increasing sensing range

546 that vision provides but rather depend on an inflated body to increase the prey

547 encounter cross section (Kiørboe 2013). The superiority of vision declines with 
ambient light so the relative disadvantage of gelatinous zooplankton versus fish

549 diminishes in turbid water or in deep waters (Sørnes \& Aksnes 2004).

\section{Life history and progeny size}

551 Though obvious on the individual level, the concept of size becomes ambiguous

552 when applied at the species level since all life differs in the size of adults and

553 progeny; even unicellular organisms need to double their size before they can

554 divide. The difference between adult and progeny size is most extreme among

555 the teleosts (bony fish) where the weight ratio between adults and larvae can be 556 up to $10^{8}$ for bluefin tuna.

558 [sidebar 2 near here]

559

560

Optimal life history theory

561 The evolution of life history with a pronounced difference between adult and

562 offspring size can be understood from optimal life history theory (Andersen et al.

563 2008, Christiansen \& Fenchel 1979). If we assume 1) standard metabolic scaling

564 of consumption $=A w^{n}$ with $n \approx 3 / 4$ (West et al. 1997); 2) metabolic scaling of

565 mortality $\alpha A w^{n-1}$ (Andersen \& Beyer 2006, Hirst \& Kiørboe 2002, Peterson \&

566 Wroblewski 1984); and 3) determinate growth, then the lifetime reproductive

567 output $R_{0}$ becomes (Sidebar 2):

568

$$
R_{0}=\frac{\epsilon}{2 \alpha}\left(\frac{W}{w_{0}}\right)^{1-\alpha}
$$


where $W / w_{0}$ is the ratio between the weight at maturation and weight of

571 offspring, $\epsilon$ is the efficiency of reproduction and $\alpha$ is the physiological mortality,

572 which is less than 1 (Andersen et al. 2008). Because the exponent $1-\alpha$ is

573 positive $R_{0}$ is an increasing function of $W / w_{0}$. The metabolic assumptions thus

574 predict an evolutionary pressure towards a life history with as large a ratio

575 between adult size and offspring size as possible. Since no organisms has an

576 infinite ratio between adult size and offspring size, a full understanding of what

577 limits actual offspring size cannot be achieved from optimal life history theory

578 based on metabolic scaling laws alone; the actual offspring size will be limited by

579 other processes.

580

581 Offspring size strategies

582 Observed offspring size strategies employed by marine life can roughly be

583 partitioned into two groups: a "fixed-ratio" strategy where offspring size is a

584 constant fraction of the adult size and a "small-eggs" strategy where offspring

585 size is the same, independent of adult size (Neuheimer et al.) (

586 Figure 7). Crustaceans, cartilaginous fish and whales employ the fixed-ratio

587 strategy with an adult:offspring weight ratio around 100:1. The metabolic

588 optimal life history theory (eq. 7) is unable to predict the fixed-ratio strategy.

589 For marine mammals the fixed-ratio strategy can be explained by the need to

590 perform parental care (Shine 1978). For the other groups, the fixed-ratio

591 strategy can be explained by an elaboration of the evolutionary argument in

592 sidebar 2, to account for density dependent effects (Olsson et al.). Such

593 elaboration shows that the strategy that maximizes $W / w_{0}$ is only optimal if the 
594 offspring do not experience density dependent effects right at the time of 595 hatching. If they do experience density dependent survival early in life, an 596 evolutionary stable strategy with $W / w_{0} \approx 100$ emerges.

\section{Transitions between life forms}

598 We have reviewed how size influences resource acquisition, mobility, ability to 599 sense prey, and life-history strategy, based on theoretical arguments and cross600 species empiric analyses. We now use these relations to understand the

601 mechanisms behind the transitions between the seven realms of marine life: 602 molecular life, osmo-heterotrophic bacteria, unicellular phototrophs, unicellular

603 mixotrophs and heterotrophs, planktonic multi-cellular heterotrophs with 604 ontogenetic growth, visually foraging poikilotherms, and homeothermic animals 605

606 Figure 1 and Table 1). These seven realms correspond to the traditional 607 taxonomic division of life between viruses, bacteria, phytoplankton, uni- and 608 multicellular zooplankton, fish and marine mammals. Our alternative naming 609 reflects the function of the groups and highlights the factor that determines the 610 characteristic size where there is a transition between the groups.

612 A central theme is that development of larger size opens new possibilities for

613 resource acquisition and sensing. Examples are how the battery of available

614 senses increases with size (

615 Figure 6), how the emergence of multicellularity makes it possible to increase 616 the adult:offspring size ratio and thereby increase fitness (Sidebar 2), or how 617 mortality decreases with size. Larger size therefore increases the competitive 
edge, provides access to new resources as well as increases survival. The sizes

619 where new possibilities appear often mark a transition between the major life

620 forms because the utilization of new senses etc. require fundamental changes in

621 body plan and life strategy.

622

623 From viruses to cells

624 The smallest size of a cell is around $10^{-15} \mathrm{~g}_{\mathrm{C}}$ with a diameter around $0.1-1 \mu \mathrm{m}$.

625 Organisms this small are believed to be functionally limited by metabolic

626 constraints (Kempes et al. 2012) and the size of non-scalable components:

627 genome size (DeLong et al. 2010) and in particular the cell wall (Raven 1994).

628 The wall size along can be used to calculate a lower limit for cell size: The wall

629 has a mass $c_{\text {wall }} d^{2}$ and the cell itself $c d^{3}$ where $c_{\text {wall }}$ and $c$ are constants. If we

630 ignore the genome a theoretical lower limit to cell size is when all cell mass is

631 used by the wall:

632

$$
d_{\text {limit }}=\frac{c_{\text {wall }}}{c}
$$

633

634 For a $0.5 \mu \mathrm{m}$ cell the wall comprises abound $30 \%$ of the total mass (Raven

635 1994), so $c_{\text {wall }} / \mathrm{c} \approx 0.3 \times 0.5 \mu \mathrm{m}$. This gives a lower limit cell size of $d_{\text {limit }} \approx 0.15$

$636 \mu \mathrm{m}$.

637

638 From osmo-heterotrophs to phototrophs

639 The smallest unicellular organisms are heterotrophic bacteria feeding on

640 dissolved organic matter encountered through diffusion. At a diameter 
$641 C_{\mathrm{DOM}} b_{D} /\left(C_{L} b_{L}\right)$ (eq. 4$)$, it becomes favourable to fix inorganic carbon through

642 photosynthesis instead of relying on dissolved organic matter. This size depends

643 on the relative concentrations of dissolved organic matter $C_{\mathrm{DOM}}$ and light $C_{L}$, but

644 it can be as small as $10^{-14} \mathrm{~g}_{\mathrm{C}}$ in the upper photic zone with concentrations of

645 dissolved organic matter $C_{\mathrm{DOM}} \approx 5 \mu \mathrm{g}$ / l and abundant light $\left(C_{L} \approx 7 \mathrm{~J} \mathrm{day}^{-1} \mathrm{~m}^{-2}\right)$

646 and increases as a light decreases (

647 Figure 4).

648

649 From phototrophs to heterotrophs

650 The smallest phototrophs are expected to be carbon limited (which in practice

651 means that they are limited by the amount of light since dissolved inorganic

652 carbon is assumed to be plentiful), while the largest phototrophs are expected to

653 be nutrient limited. This difference emerges from the different scaling of nutrient

654 encounter that scales with $l^{1}$ and light encounter that scales with $l^{2}$ (Eqs. 2 and 3

655 and

656 Figure 3). As before, the exact sizes where the transitions between light limited

657 phototrophs, nutrient limited phototrophs, and heterotrophs occur depend on

658 the specific conditions of dissolved nutrients, light and suitable prey (Figure 4b).

659 An order-of-magnitude estimation of the characteristic transition between

660 phototrophs and pure heterotrophs is $10^{-7} \mathrm{~g}_{\mathrm{C}}\left(l \approx 6 \times 10^{-2} \mathrm{~cm}\right)$, but it can vary

661 between $10^{-8} \mathrm{~g}_{\mathrm{C}}$ in low light and high nutrients situations and $10^{-5} \mathrm{~g}_{\mathrm{C}}$ in

662 situations of high light.

663 
664 The size that marks the transition between phototrophs and heterotrophs is

665 blurred by a large group of mixotrophic organisms that acquire nutrients and

666 carbon for biomass synthesis from phagotrophy while photosynthesis primarily

667 provides carbon for metabolism. The mixotrophic strategy is most favourable for

668 organisms with sizes in the transition between phototrophy and heterotrophy.

669 The size range where the mixotrophic strategy is favourable varies with

670 environmental conditions: it is vanishingly small in eutrophic conditions and

671 increases to more than a factor 10 in diameter in oligotrophic conditions, in

672 agreement with observations (Barton et al. 2013).

673

674 Unicellular to multicellular life

675 The drive to develop larger size eventually leads to multicellular organisms.

676 Multicellularity opens the possibility of specialized tissue for, e.g., sensory

677 organs. Among microscopic metazoans the dominant group of copepods has

678 developed sensory apparatus to detect prey via hydromechanical cues and

679 appendages to generate feeding currents and make jumps to escape predators.

680 We have not developed a specific argument for the size where the transition to

681 multicellularity occurs, but since life-history theory predicts that increasing

682 offspring-adult size ratio increases lifetime reproductive output (Eq. 7), it is

683 likely to occur at the smallest possible size. DeLong et al. (2010) argue that this is

684 when it becomes possible to develop a fractal delivery network, around $10^{-6} \mathrm{~g}_{\mathrm{C}}$

$685(\approx 1 \mu \mathrm{m})$. The drive towards minimization of offspring and maximization of

686 adult size means that each metazoan group strives to extend its size range, but is 
only able to do so within the limits defined by the sizes where there is a breakdown in a scaling relationship describing a vital function.

From copepods to fish

691 Fish (including cephalopods) are the dominant organisms in the size-range from

$6921 \mathrm{mgww}$ to about $100 \mathrm{~kg}(1 \mathrm{~cm}$ to $2 \mathrm{~m})$. Fish are characterized by being

693 streamlined, visual predators. At a size smaller than $1 \mathrm{mgww}_{\mathrm{w}}$ the dominating

694 organisms are blind copepods, with a very non-streamlined body plan. The transition size between these two very different life forms is characterized by the transition from the superior sensing mode being mechanosensing to vision and

697 the transition from a viscous to an inertial hydromechanical regime. The change

698 in hydromechanical regime explains the slender fish shape, but it also entails a 699 change in feeding mode. Fish larvae employ suction feeding, which becomes 700 increasingly difficult the smaller they are (China \& Holzman 2014). Probably the 701 most important transition is in sensing, with the lower size limit of fish 702 coinciding with the lower size of a functioning eye. Were fish to make smaller 703 eggs their larvae would be unable to compete with the tactile sensing copepod 704 with a morphology designed for optimal movement and prey capture in a viscous 705 fluid environment; were copepods to become larger they would be outcompeted 706 by visually sensing fish with streamlined bodies.

708 From fish to whales

709 Whales are the largest organisms in the oceans, occupying the size range from 710 about $100 \mathrm{~kg}$ and up. It is tempting to attribute the transition from fish to whales 
711 to the appearance of echolocation as a possible sensing mode. However, only

712 toothed whales employ echolocation for sensing, whereas baleen whales rely on

713 the same senses as fish. If there are no change in the power law relationships

714 determining sensing and food encounter, why, then, have teleosts not evolved

715 even larger sizes than the few hundred kilos of the largest fish (bluefin tuna or

716 sunfish with maximum weights of 450 and $1000 \mathrm{kgww}_{\mathrm{w}}$ ? We propose two

717 arguments for the transition between fish and marine mammals: a metabolically

718 based upper limit of a water-breathing organism (Freedman \& Noakes 2002;

719 Makarieva et al. 2004, Supp.) and a lower size limit of a homeothermic (warm-

720 blooded) organism.

722 We have focused on acquisition of resources in terms of carbon and nutrients,

723 but heterotrophs also need oxygen to fuel their metabolism. The absorption of

724 oxygen through gills is limited by the surface of the gills. Since the surface of gills

725 is fractal it will scale with an exponent between $2 / 3$ and 1 , probably very close to

726 the metabolic exponent of 3/4. The acquisition of oxygen therefore scales with a

727 similar exponent as metabolism, so the relative ability to acquire food and

728 oxygen is independent of size. However, larger organisms accumulate heat

729 created by activity and use this to elevate their metabolism. Notable examples

730 are the scombroids (tuna and marlin) and pelagic sharks (Block 1991). A high

731 body temperature means higher activity and therefore higher predatory success

732 against slower heterothermic (cold-blooded) prey. Such an increase in

733 metabolism will eventually require more oxygen than can be obtained by

734 pumping water over the gills. This problem is solved by ram ventilation, which 
735 provides a higher flow of water around the gills and therefore a higher oxygen

736 absorption rate. Evidence for this is provided by the largest fish being either very

737 active ram-ventilating (large scombroids or sharks) or relatively sluggish

738 pumping (sunfish). We conjecture that it would be impossible for fish to develop

739 homeothermy as a means of competing with marine mammals; the solubility of

740 oxygen in water is simply too low to fuel a homeothermic metabolism. Marine

741 mammals fuel their high homeothermic metabolism by breathing air, which has

742 a much higher solubility of oxygen than water.

743

744 For homeotherms the loss of body heat should be included in the energy budget

745 as this defines a lower limit for the size of a homeotherm (Haldane 1928). Heat

746 loss is a surface process that scales as $\propto \kappa w^{2 / 3}$ where $\kappa$ is the thermal

747 conductivity of water. Since organisms wish to minimize heat loss their surface is

748 not fractal and the exponent is not larger than $2 / 3$. The energy for heating comes

749 from the acquisition of resources (oxygen and food), which scales metabolically

750 as $A w^{3 / 4}$. The size where there is a balance between loss of heat and acquisition

751 of resources defines a lower limit of homeothermy as $(A / \kappa)^{12}$ (Andersen et al.

752 2008). This lower limit is very sensitive to the value of the parameters $A$ and $\kappa$

753 since their ratio is raised to a high exponent. For example, the ratio between the

754 lower limits calculated for a marine and a terrestrial habitat is the ratio between

755 the heat conductivity in air and water $(\approx 20)$, raised to power 12 which gives

$7564 \times 10^{15}$. This factor is much larger than the ratio between the smallest whale, a

757 harbour porpoise calf of around $10 \mathrm{~kg}$, and the smallest terrestrial homeotherm,

758 an Etruscan shrew (Suncus etruscus) at around $0.1 \mathrm{~g}$. Nevertheless it seems 
evident that the smallest land animals are limited by loss of heat, e.g. shrews

760 huddle together to conserve heat, so how can whales manage to attain a small

761 size in the face of a larger heat loss? We hypothesise that whales do that by

762 having an insulating layer of blubber. To achieve a lower size of $10 \mathrm{~kg}$ (a factor

$76310^{6}$ smaller than predicted), whales need to decrease heat losses by a factor

$76410^{6 / 12} \approx 3.2$ relative to terrestrial animals, which is not out of scope.

\section{Beyond size}

766 We posit that individual size is the most important trait characterizing a pelagic

767 organism. Knowing the size, it is possible to estimate, often within an order of

768 magnitude, the metabolic rate, the clearance rate, the swimming speed and the

769 sensory range. We have shown how that information facilitates inference of

770 trophic strategy, sensory mode, body shape, and, to some degree, reproductive

771 strategy. Though important, we have largely ignored the subtle interplay

772 between temperature, oxygen concentration and size (Verberk \& Atkinson

773 2013). Even though size can be characterized as a "master trait" (Litchman \&

774 Klausmeier 2008), it is not the only trait that characterizes an organism. The

775 relevant question is then which other traits best characterize the variation

776 around the mean in the reviewed relations with size (

777 Figure 2, 5 and 7). We propose three candidate traits to consider: predator-prey

778 size ratio, "feeding mode" for heterotrophic metazoans and "jellyness".

780 Among heterotrophic metazoans there appear to be two dominant strategies to

781 predator-prey size ratio: a fixed predator-prey length ratio in the range 10-100,

782 which is the strategy followed by most fish and copepods (Barnes et al. 2008), or 
a strategy aimed at preying on organisms much smaller than the predator. The

784

785

786

787

788

789

790

791

792 small-prey strategy is used by the largest zooplankton, the pelagic tunicates, and by the largest vertebrates, the whale sharks and the baleen whales. Organisms with a large predator-prey size ratio rely on filtering the water to catch the prey. It is presently unknown what drives the development of the two alternative, but apparently equally competitive, strategies.

The feeding mode determines whether an actively feeding predator encounters its prey through ambushing or cruising. It is often assumed that predation pressure is a function of size only and therefore independent of feeding strategy or sensing mode. This is not quite true. It is becoming increasingly evident that feeding strategy is associated with a trade-off in mortality: an ambush feeder will encounter less prey than a cruising predator but it will also have less exposure to predation and therefore lower mortality. A quantitative demonstration of this trade-off has been made for zooplankton based on laboratory experiments (Kiørboe 2013b) and the importance for the seasonal succession has been modelled (Mariani et al. 2013). These trade-offs likely apply at least qualitatively to other predators, e.g. fish.

A related trade-off is the development of a gelatinous body (jellyfish, box jellies and pelagic tunicates). We argued in section "sensing" that visual predators would be superior to predators sensing their prey through hydromechanical forces. However, the inflated body size of gelatinous organisms results in a large encounter cross-section and hence a higher clearance rate than a non-gelatinous 

strategy effective even in the same size range where visual predation is possible

809 (Acuña et al. 2011), particularly under low light conditions (Sørnes \& Aksnes

810 2004). At the same time the gelatinous body makes the organism less attractive

811 to predators thereby lowering its mortality. These two examples show how the

812 general "rules" inferred from size scaling of encounter, mobility, and sensing can

813 be transgressed by other traits.

\section{Acknowledgements}

815 KHA thanks Mick Follows for hospitality at MIT while the draft of this

816 manuscript was written. This work is part of the "Centre for Ocean Life", a VKR

817 center of excellence supported by the Villum foundation

\section{Literature cited}

819 Acuña JL, López-Urutia Á, Colin S. 2011. Faking giants: the evolution of high prey clearance rates in jellyfishes. Science. 333(6049):1627-29

821 Aksnes D, Egge J. 1991. A theoretical model for nutrient uptake in phytoplankton. Mar. Ecol. Prog. Ser. 70(1980):65-72

823 Aksnes D, Utne A. 1997. A revised model of visual range in fish. Sarsia, pp. 137-47

824 Andersen KH, Beyer JE. 2006. Asymptotic size determines species abundance in the marine size spectrum. Am. Nat. 168:54-61

826 Andersen KH, Beyer JE, Pedersen M, Andersen NG, Gislason H. 2008. Life-history constraints on 
Christiansen FB, Fenchel TM. 1979. Evolution of marine invertebrate reproductive patterns.

Ara R, Amin SMN, Mazlan AG, Arshad A. 2013. Morphometric variation among six families of larval fishes in the Seagrass-Mangrove ecosysetm of Gelang Patah, Johor, Malaysia. Asian J. Anim. Vet. Adv. 8(2):247-56

Bagøien E, Kiørboe T. 2005. Blind dating - mate finding in planktonic copepods. I. Tracking the pheromone trail of Centropages typicus. Mar. Ecol. Prog. Ser. 300:105-15

Barnes C, Bethea DM, Brodeur RD, Spitz J, Ridoux V, et al. 2008. Predator and prey body sizes in marine food webs. Ecology. 89(3):881

Barton AD, Finkel Z V., Ward B a., Johns DG, Follows MJ. 2013. On the roles of cell size and trophic strategy in North Atlantic diatom and dinoflagellate communities. Limnol. Oceanogr. 58(1):254-66

Bejan A, Marden JH. 2006. Unifying constructal theory for scale effects in running, swimming and flying. J. Exp. Biol. 209(Pt 2):238-48

Berg HC, Purcell EM. 1977. Physics of chemoreception. Biophys. J. 20:193-219

Block BA. 1991. Evolutionary novelties: how fish have built a heater out of muscle. Am. Zool.

$$
31: 726-42
$$

Boudreau PR, Dickie LM. 1992. Biomass spectra of aquatic ecosystems in relation to fisheries yield. Can. J. Fish. Aquat. Sci. 49(8):1528-38

Charnov EL. 1993. Life History Invariants. Oxford University Press, Oxford, England

China V, Holzman R. 2014. Hydrodynamic starvation in first-feeding larval fishes. Proc. Natl. Acad. Sci. U. S. A. 111(22):8083-88 
Cohen J, Pimm S, Yodzis P, Saldaña J. 1993. Body sizes of animal predators and animal prey in food webs. J. Anim. Ecol. 62:67-78

Collin SP, Whitehead D. 2004. The functional roles of passive electroreception in non-electric fishes. Anim. Biol. 54:1-25

Curcio CA, Sloan KR, Kalina RE, Hendrickson AE. 1990. Human photoreceptor topography. J. Comp. Neurol. 292(4):497-523

Davies-Colley RJ, Smith DG. 1995. Optically pure waters in Waikoropupu ('Pupu') Springs, Nelson, New Zealand. New Zeal. J. Mar. Freshw. Res. 29:251-56

DeLong JP, Okie JG, Moses ME, Sibly RM, Brown JH. 2010. Shifts in metabolic scaling, production, and efficiency across major evolutionary transitions of life. Proc. Natl. Acad. Sci. U. S. A. 107(29):12941-45

Dunbrack RL, Ware DM. 1987. Energy constraints and reproductive trade-offs determining body size in fishes. In Evolutionary Physiological Ecology, ed. P Calow, pp. 191-218

Dusenbery DB. 2009. Living at Micro Scale: The Unexpected Physics of Being Small. Harvard University Press

Edwards KF, Thomas MK, Klausmeier CA, Litchman E. 2012. Allometric scaling and taxonomic variation in nutrient utilization traits and maximum growth rate of phytoplankton. Limnol.

868 Fenchel T. 1974. Intrinsic rate of natural increase: the relationship with body size. Oecologia.

$$
14: 317-26
$$
NATO Conf. Ser. 11:301-15 
872 Fenchel T, Finlay BJ. 2004. The ubiquity of small species: patterns of local and global diversity. Bioscience. 54(8):777-84

874

875

876

877

878

Fiksen $\emptyset$, Follows M, Aksnes D. 2013. Trait-based models of nutrient uptake in microbes extend the Michaelis-Menten framework. Limnol. Ocean. 58(1):193-202

Finkel ZV. 2001. Light absorption and size scaling of light-limited metabolism in marine diatoms. Limnol. Oceanogr. 46(1):86-94

Freedman JA, Noakes DLG. 2002. Why are there no really big bony fish? A point-of-view on maximum body size in teleosts and elasmobranchs. Rev. Fish Biol. Fish. 12:403-16

Froese R, Pauly D. 2013. FishBase. www.fishbase.org

Gillooly J, Charnov E, West G, Savage V, Brown J. 2002. Effects of size and temperature on developmental time. Nature. 417:70-73

Haldane JBS. 1928. On being the right size. In A Treasure of Science, p. 321

Hansen B, Bjørnsen PK, Hansen PJ. 1994. The size ratio between planktonic predators and their prey. Limnol. Oceanogr. 39(2):395-403

Hansen PJ, Bjørnsen PK, Hansen BW. 1997. Zooplankton grazing and growth: scaling within the 2--2.000 $\mu \mathrm{m}$ body size range. Limnol. Oceanogr. 42(4):687-704

Hemmingsen AM. 1960. Energy metabolism as related to body size and respiratory surfaces, and its evolution. Rep. Steno Mem. Hosp. 9(11):7-110

Hirst AG, Kiørboe T. 2002. Mortality of marine planktonic copepods: global rates and patterns. Mar. Ecol. Prog. Ser. 230:195-209 91:385-98 

elasmobranchs. Biol. sharks their Relat., pp. 325-68

Huntley ME, Zhou M. 2004. Influence of animals on turbulence in the sea. Mar. Ecol. Prog. Ser. 273:65-79

Kempes CP, Dutkiewicz S, Follows MJ. 2012. Growth, metabolic partitioning, and the size of microorganisms. Proc. Natl. Acad. Sci. U. S. A. 109(2):495-500

Kiørboe T. 1993. Turbulence, phytoplankton cell size, and the structure of pelagic food webs. Adv. Mar. Biol. 29:1-72

Kiørboe T. 2001. Formation and fate of marine snow: small-scale processes with large-scale implications. Sci. Mar. 65(Supp. 2):57-71

Kiørboe T. 2011. How zooplankton feed: mechanisms, traits and trade-offs. Biol. Rev. Camb. Philos. Soc. 86(2):311-39

Kiørboe T. 2013. Zooplankton body composition. Limnol. Oceanogr. 58:1843-50

907

908

Kiørboe T, Hirst AC. 2014. Shifts in mass-scaling of respiration, feeding, and growth rates across

911 Klausmeier C, Litchman E, Daufresne T, Levin S. 2004. Optimal nitrogen-to-phosphorus

913 Kleiber M. 1932. Body size and metabolism. Hilgardia. 6:315-53

914 Litchman E, Klausmeier CA. 2008. Trait-Based Community Ecology of Phytoplankton. Annu. Rev. Ecol. Evol. Syst. 39(1):615-39 
916 Litchman E, Klausmeier CA, Schofield OM, Falkowski PG. 2007. The role of functional traits and

917 trade-offs in structuring phytoplankton communities: scaling from cellular to ecosystem

$918 \quad$ level. Ecol. Lett. 10(12):1170-81

919 Makarieva AM, Gorshkov VG, Bai-Lian L. 2004. Ontogenetic growth: models and theory. Ecol. $920 \quad$ Modell. 176:15-26

921 Marañón E, Cermeño P, López-Sandoval DC, Rodríguez-Ramos T, Sobrino C, et al. 2013. Unimodal 922 size scaling of phytoplankton growth and the size dependence of nutrient uptake and use. $923 \quad$ Ecol. Lett. 16(3):371-79

924 Mariani P, Andersen KH, Visser AW, Barton AD, Kiørboe T. 2013. Control of plankton seasonal succession by adaptive grazing. Limnol. Oceanogr. 58(1):173-84 Sensory Hierarchy in Ocean Life. Submitt. Publ.

May R, Godfrey J. 1994. Biological diversity: differences between land and sea. Proc. R. Soc. B Biol. Sci. $343: 105-11$

Mei Z-P, Finkel Z V, Irwin AJ. 2009. Light and nutrient availability affect the size-scaling of growth in phytoplankton. J. Theor. Biol. 259(3):582-88

Morel A, Bricaud A. 1981. Theoretical results concerning light absorption in a discrete medium, and application to specific absorption of phytoplankton. Deep Sea Res. Part. 28A(11):1375-

Morioka S, Vongvichith B, Phommachan P, Chantasone P. 2013. Growth and morphological development of laboratory-reared larval and juvenile bighead catfish Clarias macrocephalus (Siluriformes: Clariidae). Ichtyology Res. 60:16-25 
Moser HG, Sumida BY, Ambrose DA, Sandknop EM, Stevens EG. 1986. Development and distribution of larvae and pelagic juveniles of ocean whitefish, Caulolatilus princeps, in the Calcofi survey region. CalCOFI Rep. XXVII:

942 Munk WH, Riley GA. 1952. Absorption of nutrients by aquatic plants. J. mar. Res. 11:215-40

943 Neuheimer AB, Hartvig M, Heuschele J, Hylander S, Kiørboe T, et al. Adult and offspring size in the 944 ocean over 17 orders of magnitude follows two life-history strategies. Submitt. Publ.

945 Northmore D, Volkmann FC, Yager D. 1978. Vision in fishes: colour and pattern. In The Behavior of Fish and Other Aquatic Animals, ed. DI Mostofsky, pp. 79-136. Academic press

947 Oka S, Higashiji T. 2012. Early Ontogeny of the big roughy Gephyroberex japonicus

948 (Beryciformes: Trachichtyidae) in captivity. Ichtyology Res. 59:282-85

949 Olsson K, Gislason H, Andersen KH. Dual offspring size strategies in fish. Submitt. Publ.

Peters RH. 1983. The Ecological Implications of Body Size. Cambridge University Press

951 Peterson I, Wroblewski J. 1984. Mortality Rate of Fishes in the Pelagic Ecosystem. Can. J. Fish. Aquat. Sci. 41:1117-20

Rall BC, Brose U, Hartvig M, Kalinkat G, Schwarzmüller F, et al. 2012. Universal temperature and body-mass scaling of feeding rates. Philos. Trans. R. Soc. B Biol. Sci. 367:2923-34

955 Raven JA. 1994. Why Are There No Picoplanktonic 02 Evolvers with Volumes Less Than $10^{\wedge}-19$ m3? J. Plankton Res. 16:565-80 Anim. Ecol. 83(4):963-79 length of fishes. Fishbyte. 8(3):16-20 
961 Schwaderer AS, Yoshiyama K, de Tezanos Pinto P, Swenson NG, Klausmeier CA, Litchman E. 2011. Eco-evolutionary differences in light utilization traits and distributions of freshwater phytoplankton. Limnol. Oceanogr. 56(2):589-98

964 Sheldon R, Prakash A. 1972. The size distribution of particles in the ocean. Limnol. Oceanogr. XVII(May):327-40

Sheldon RW, Sutcliffe Jr. WH, Paranjape MA. 1977. Structure of pelagic food chain and relationship between plankton and fish production. J. Fish. Res. Board Canada. 34:2344-53

Shine R. 1978. Propagule size and parental care: the "safe harbor" hypothesis. J. Theor. Biol. 75(4):417-24

Sørnes TA, Aksnes DL. 2004. Predation efficiency in visual and tactile zooplanktivores. Limnol. Oceanogr. 49(1):69-75

Stoecker DK. 1998. Conceptual models of mixotrophy in planktonic protists and some ecological and evolutionary implications. Eur. J. Protistol. 34:281-90

974 Taguchi S. 1976. Relationship between photosynthesis and cell size of marine diatoms. J. Phycol. 12:185-89

Tambi H, Flaten G, Egge J, Bødtker G, Jacobsen A, Thingstad TF. 2009. Relationship between phosphate affinities and cell size and shape in various bacteria and phytoplankton. Aquat.

979 Tennekes H, Lumley JL. 1972. A First Course in Turbulence. The MIT press 
982 Verberk WCEP, Atkinson D. 2013. Why polar gigantism and Palaeozoic gigantism are not equivalent: effects of oxygen and temperature on the body size of ectotherms. Funct. Ecol.

984 $27(6): 1275-85$

985 Visser A. 2001. Hydromechanical signals in the plankton. Mar. Ecol. Prog. Ser. 222:1-24

986

987

988

989

990

991

992

993

994

995

996

997

998

Visser AW, Jackson GA. 2004. Characteristics of the chemical plume behind a sinking particle in a turbulent water column. Mar. Ecol. Pro. Ser. 283:55-71

Ware DM. 1978. Bioenergetics of pelagic fish: theoretical change in swimming speed and ration with body size. J. Fish. Res. Board Canada. 35:220-28

Watkins JL, Brierley AS. 2002. Verification of the acoustic techniques used to identify Antarctic kril. ICES J. Mar. Sci. 59(6):1326-36

Webb P. 1988. Simple physical principles and vertebrate aquatic locomotion. Am. Zool. 28(2):709-25

West GB, Brown JH, Enquist BJ. 1997. A general model for the origin of allometric scaling laws in biology. Science. 276(5309):122-26

Winberg GG. 1956. Rate of metabolism and food requirements of fishes. J. Fish. Res. Board Canada. 194:1-253 
Power law: $y=a x^{b}$ with factor $a$ and exponent $b$. Linear regression employs a $1003 \operatorname{logarithmic}$ transformation: $\log y=\log a+b x$, with $\log a$ being "intercept" and $b$ 1004 the "slope".

1005

Poikilotherm: An organism that maintains the same body temperature as the 1007 environment, in contrast to a homeotherm which maintains a constant body 1008 temperature due to internal heat sources.

Protists are simple, typically unicellular, eukaryotic organisms, living in aquatic 1011 environments.

1013 An organisms' trophic strategy describes how it gathers nourishment. The 1014 suffix "troph" derives from ancient greek: trophe=food, nourishment; drepo=to 1015 gather.

1017 Phototrophs rely on photosynthesis as their carbon source and use 1018 osmotrophic diffusive uptake of nutrients. In contrast phagotrophs up carbon 1019 and nutrients by absorbing other living organisms. Mixotrophs employ a mixed 1020 strategy, typically combining photosynthesis with phagotrophy. 
1023 Cartilaginous fish (Chondrichthyes) are fish with skeletons made of cartilage

1024 rather than bone, containing elasmobranchs (sharks, rays and skates) and

1025 Holocepahlii ("ghost sharks").

1026

1027 Cephalopods are squid, octopi and cuttlefish, commonly referred to as "inkfish".

1028

1029 The physiological mortality is the ratio between mortality and weight-specific

1030 consumption. With metabolic scaling of uptake $A w^{3 / 4}$ and mortality $c w^{-1 / 4}$ the

1031 physiological mortality becomes $\alpha=c / A$.

1032

1033 Stresslet: A stokes flow produced by 2 co-linear anti-parallel point forces acting 1034 on a fluid. 
1036 Table 1. Characteristic sizes of transitions between major realms of life in the 1037 ocean.

\begin{tabular}{|c|c|c|}
\hline Transition & Size & Notes \\
\hline Lower size of a cell & $0.15 \mu \mathrm{m} \approx 10^{-15} \mathrm{~g}_{\mathrm{C}}$ & $\begin{array}{l}\text { Limited by cell wall and to a lesser extent } \\
\text { genome size (Eq. 8) }\end{array}$ \\
\hline $\begin{array}{l}\text { Osmo-heterotrophs to } \\
\text { phototrophs }\end{array}$ & $10^{-14}$ to $10^{-13} \mathrm{~g}_{\mathrm{C}}$ & $\begin{array}{l}\text { Transition from diffusion feeding on } \\
\text { DOM to photosynthesis (Eq. 4). }\end{array}$ \\
\hline Phototrophs to mixotrophs & $10^{-8} \mathrm{~g}_{\mathrm{C}}$ & $\begin{array}{l}\text { Transition from acquiring inorganic } \\
\text { nutrients by diffusion feeding to } \\
\text { acquiring nutrients by active feeding (Eq. } \\
\text { 5) }\end{array}$ \\
\hline Mixotrophs to heterotrophs & $\begin{array}{l}10^{-7} \mathrm{~g}_{\mathrm{C}} \\
\left(10^{-8} \text { to } 10^{-5} \mathrm{~g}_{\mathrm{C}}\right)\end{array}$ & $\begin{array}{l}\text { Acquisitions of carbon and nutrients } \\
\text { solely by predation through active } \\
\text { feeding (Eq. 6) }\end{array}$ \\
\hline $\begin{array}{l}\text { Single- to multicellular } \\
\text { organisms }\end{array}$ & $10^{-6} \mathrm{~g}_{\mathrm{C}}$ & Development of vascular networks. \\
\hline Copepods to fish & $\approx 1 \mathrm{mg}_{\mathrm{ww}}$ & Smallest size of a functional camera eye \\
\hline Fish to whales & $\approx 10 \mathrm{~kg}_{\mathrm{ww}}$ & $\begin{array}{l}\text { Lower size of maintaining a } \\
\text { homeothermic metabolism }\end{array}$ \\
\hline
\end{tabular}


Sidebar 1: The Dunbrack and Ware model of visual range

The maximum visual range in clear water can be estimated by considering the properties of a pin-hole camera eye as done in a largely unrecognized work by Dunbrack and Ware (1987). Here we provide a simplified derivation of their argument, which corrects a number of minor errors.

The projection of a visual image of a prey on the retina of a predator activates a number of visual elements $n$ proportional to the area of the projected image multiplied by the density of visual elements. Since we are interested in the maximum distance $R$ that an object can be discerned we can assume that the distance is large relative to the diameter of the eye such that the curvature of the eye can be ignored. The number of activated visual elements is: $n \propto \rho l_{\text {eye }}^{2} l_{\text {prey }}^{2} R^{-2}$ where $\rho$ is the density of visual elements and $l_{\text {eye }}$ is the diameter of the eye. The density of visual elements is a decreasing function of the size of the eye: $\rho \propto l_{\text {eye }}^{-d}$ with $d \approx 0.5$ (Dunbrack \& Ware 1987). Assuming that the size of the eye and the preferred size of the prey scales with the length of the predator gives the number of visual elements as

$$
n \propto l^{4-d} R^{-2}
$$

The largest distance $R$ that a predator can discern a prey of size (length) $l_{\text {prey }}$ is when the apparent contrast (the difference between the visual imprint of the prey and the background) of the prey $C_{a}$ equals the contrast threshold that the predator can distinguish $C_{t}$. Apparent contrast of the prey declines away from the 
inherent contrast $C_{0}=0.3$ as:

$$
C_{a}=C_{0} e^{-\alpha R}
$$

Where $\alpha=0.001 \mathrm{~cm}^{-1}$ is the attenuation of light by the water. The contrast threshold is a declining function of the number of visual elements $n$ involved in discerning the object:

$$
C_{t}=C_{t \cdot \min }+1 / n
$$

where $C_{t \text { min }}=0.15$ is the minimum contrast threshold for vision which depends on the ambient light. This semi-heuristic relationship is known as "Ricco's law" (Northmore et al. 1978). The maximum distance where the prey can be perceived is when the apparent contrast reaches the contrast threshold, $C_{a}=C_{t}$ :

$$
C_{0} e^{-\alpha R}=C_{t \cdot \min }+K R^{2} l^{d-4}
$$

where $K=0.025 \mathrm{~cm}^{1.5}$ is a constant which characterizes the sensitivity of the eye. It is not possible to isolate $R$ from the expression above. However, two limiting cases can be derived: 1) the "clear-water" limit is when the visual range is limited by the resolution of the eye, i.e. where $e^{-\alpha R} \approx 1$ and $C_{0} \gg C_{t \cdot \min }$ :

$$
R \approx \sqrt{C_{0} / K} l^{2-d / 2}
$$

In this case the maximum visual range increases with $l^{2-2 / d} \approx l^{1.75}$ for $d=0.5 .2$ ) 
The "turbid-water" limit is when the visual range is limited by the sensitivity (the minimum contrast threshold) of a visual element, when $C_{t \text {.min }} \gg K R^{2} l^{4-d}$ :

$$
R \approx \frac{\ln C_{o}-\ln C_{t \cdot \min }}{\alpha}
$$

In this limit the size of the predator does not play a role and the minimum contrast threshold essentially limits the visual range. The visual range decreases if the light in the water is limited (lower minimum contrast threshold $C_{t . \min }$ ) or the turbidity $\alpha$ is increased. The prediction of this limit has been subject of more elaborate models (Aksnes \& Utne 1997). 
Sidebar 2 Life-history optimization of offspring size

The optimal life history strategy in terms of offspring size and adult size is the strategy that maximizes lifetime reproductive output (Charnov 1993). In optimal life history theory lifetime reproductive output is determined by the mortality and the available energy as functions of size or age. Here we determine the offspring size which maximizes lifetime reproductive out using arguments from Christiansen \& Fenchel (1979) and Andersen et al. (2008).

The available energy can be assumed from metabolic scaling arguments to be $H(w)=A w^{n}$ where the usual metabolic assumption is $n=3 / 4$ (West et al. 1997). Consumption results in a mortality on their prey of $\mu(w)=\alpha w^{n-1}$ where $\alpha$ is a dimensionless constant relating consumption and mortality (Andersen \& Beyer 2006). For simplicity we assume determinate growth where a juvenile uses all acquired energy for growth and a mature individual of size $W$ uses all energy for reproduction; however the central results are valid for indeterminate growth as well (Andersen et al. 2008). The lifetime reproductive output (expected number of offspring during life) is:

$$
R_{0}=\frac{\epsilon}{2} P_{w_{0} \rightarrow W} \frac{H(W)}{w_{0} \mu(W)}
$$

where $\epsilon$ is the reproductive efficiency, $1 / 2$ assumes an even sex ratio, $H(W)$ is the adult rate of reproduction (mass per time), $1 / \mu(W)$ is the expected adult lifespan, $1 / \mathrm{w}_{0}$ is to convert from units of mass to number of offspring, and the probability 
to survive from offspring size $w_{0}$ to adult size $W$ is:

$$
P_{w_{0} \rightarrow W}=\exp \left[-\int_{w_{0}}^{W} \frac{\mu(w)}{H(w)} d w\right]
$$

Inserting the metabolic assumptions, $H(w)=A w^{n}$ and $\mu(w)=\alpha A w^{n-1}$ yields a lifetime reproductive output of:

$$
R_{0}=\frac{\epsilon}{2 \alpha}\left(\frac{W}{w_{0}}\right)^{1-\alpha}
$$

Three conclusions can be drawn from this result:

1) If $R_{0}<1$ each female produces less than a single offspring throughout life yielding an unsustainable population. This happens when $\alpha>1$ and it can be concluded that $\alpha<1$.

2) Lifetime reproductive output only depends on the ratio between adult size and offspring size. The absolute values of the two sizes do not matter.

3) The larger the ratio between adult and offspring size, the higher the fitness. Organisms will therefore strive to maximize this ratio under the constraints of other external factors (Neuheimer et al.).

The results do not depend on the value of the metabolic exponent $n$ as long as $n<1$. This argument ignored the maintenance metabolism and indeterminate growth to simplify the mathematical derivation, but both of these effects can be 
accounted for (Andersen et al. 2008).

1042

1043 


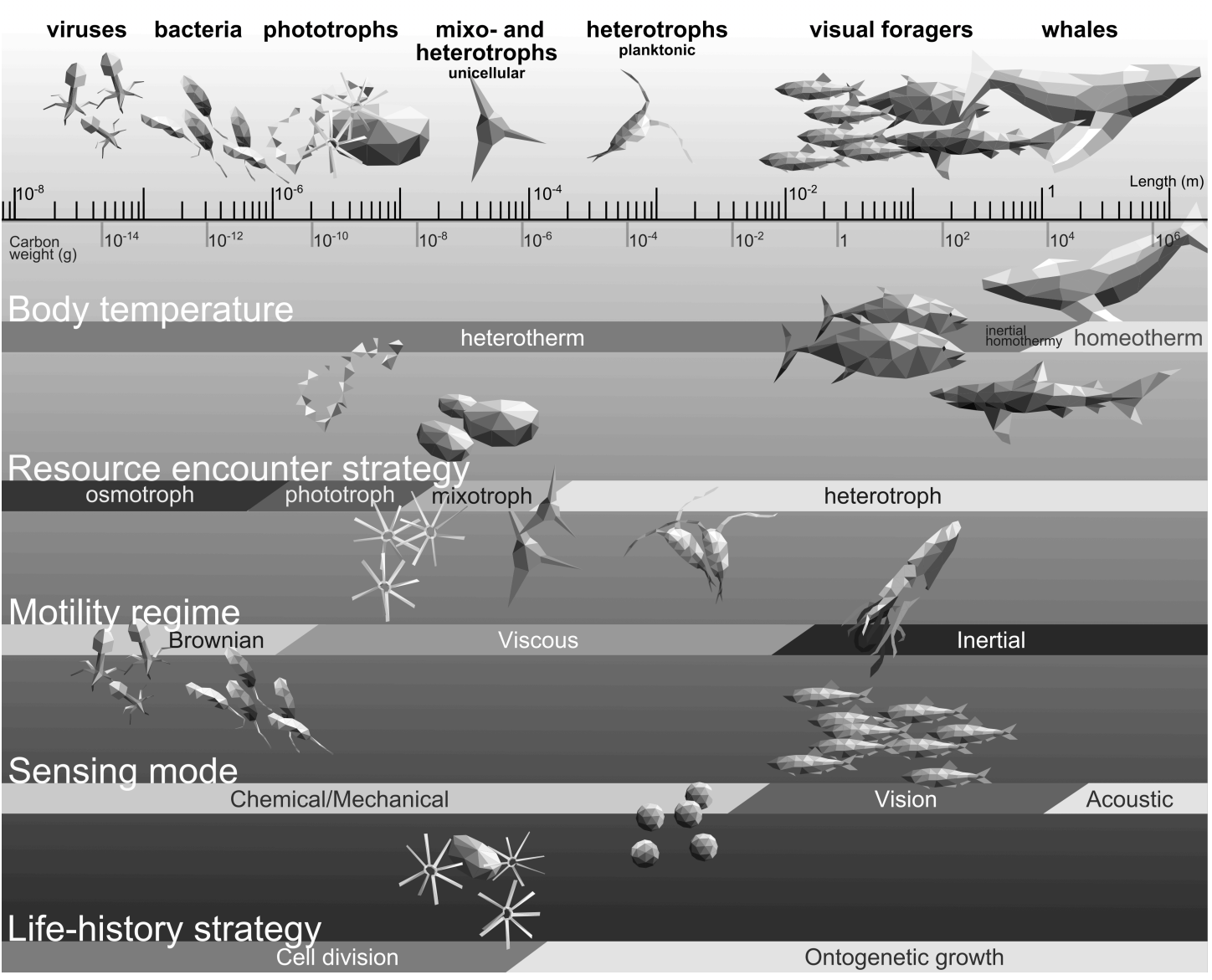

1047 Figure 1. The five aspects of pelagic marine life examined here (body temperature, resource encounter strategy, motility regime, sensing mode and

1049 life-history strategy) are illustrated with horizontal bars with the characteristic 1050 transitions indicated by changes in gray-scale. The transitions are explained 1051 throughout the text. The drawings in the top row illustrate the seven realms of 1052 life: viruses, osmo-heterotrophic bacteria, unicellular phototrophs, unicellular 1053 mixo- and heterotrophs, planktonic multi-cellular heterotrophs, visually foraging 1054 poikilotherms (teleosts, cephalopods and sharks) and homeothermic animals 1055 (whales). 

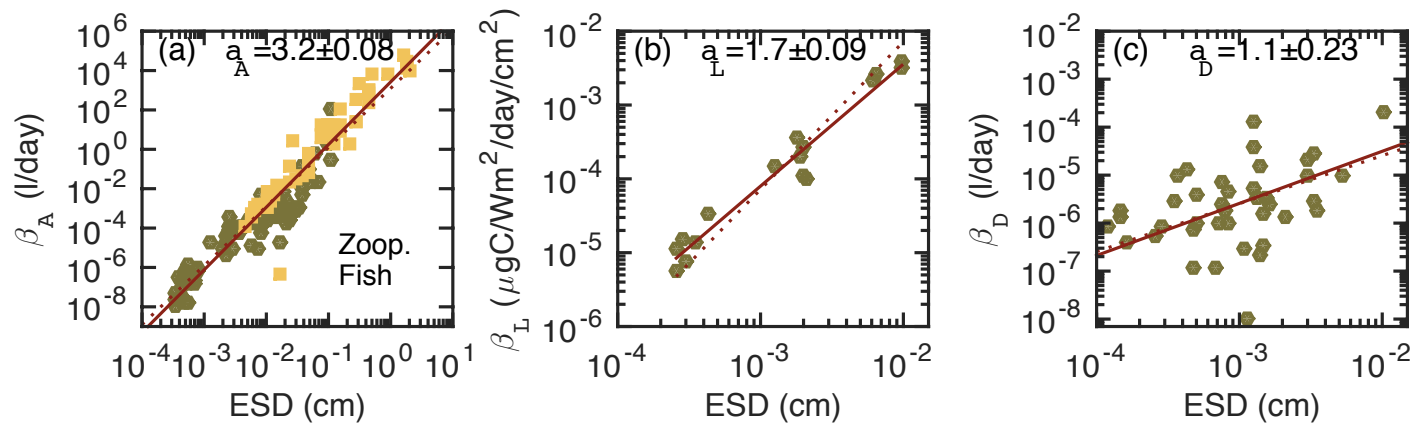

1058 Figure 2. Clearance rate vs. weight for organisms performing active predation,

1059 photosynthesis and diffusive feeding on phosphorous. The solid lines are fits to

1060 data with exponent given in each panel. The dashed lines are fits with theoretical

1061 exponents 3, 2 and 1 for panel a, b and c respectively (Table S1.2). (a) Clearance

1062 rate $\beta_{A}$ for active predation by zooplankton (circles) and fish (squares) from

1063 Kiørboe (2011). (b) Clearance rate $\beta_{L}$ (affinity) for carbon uptake from a series

1064 of experiments with diatoms under identical conditions (Taguchi 1976). Data

1065 compilations covering a wider range of sizes and phytoplankton groups give a

1066 similar exponent but a larger scatter (Schwaderer et al. 2011). (c) Clearance rate

$1067 \beta_{D}$ (affinity) for diffusive feeding on dissolved phosphate from Tambi et al.

1068 (2009) and Edwards et al. (2012). 


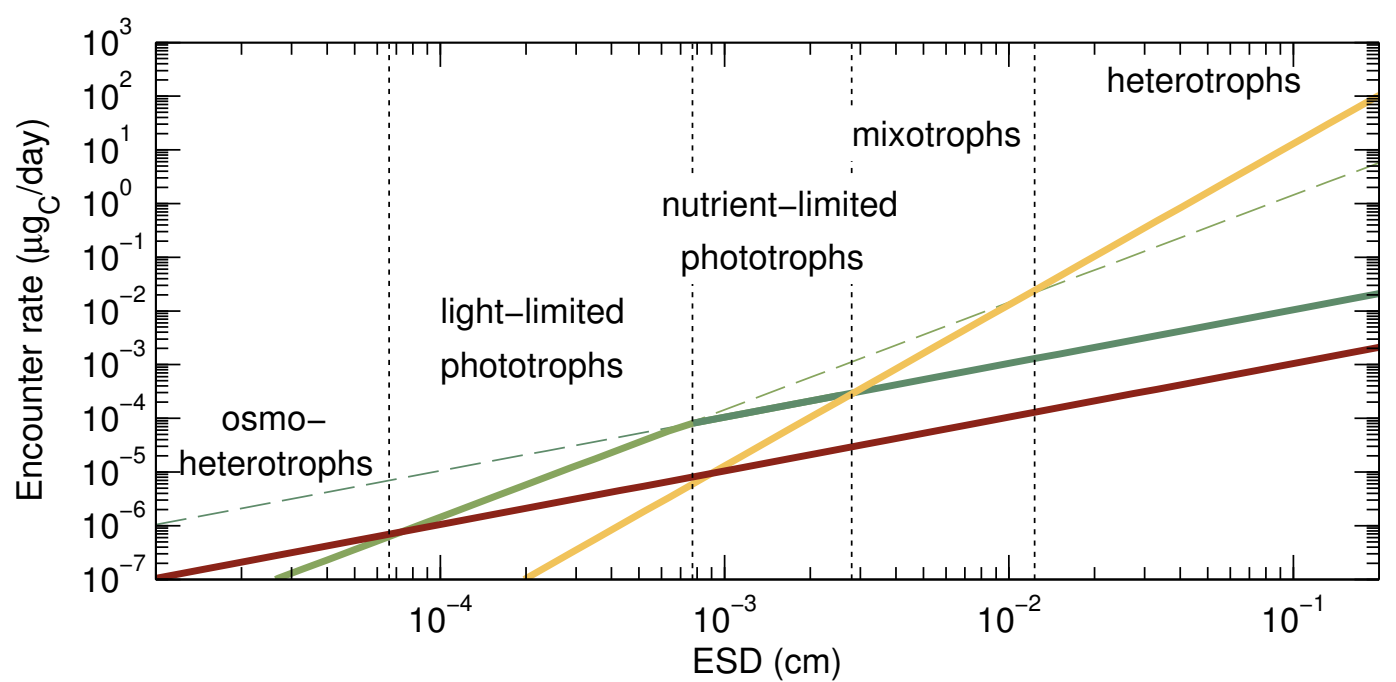

1072 Figure 3. Encounter rates as a function of size for four different resource

1073 acquisition mechanisms and resource types: diffusive uptake of dissolved

1074 organic matter scaling as $l^{1}$ (dark red), uptake of carbon through photosynthesis

1075 scaling as $l^{2}$ (light green), diffusive uptake of dissolved inorganic nutrients (dark

1076 green), and active encounter of prey organisms scaling as $l^{3}$ (yellow). The

1077 combined uptake of carbon and nutrients by phototrophs is limited by Liebig's

1078 law and shown with solid green lines; light green for light-limited conditions and

1079 dark green for nutrient-limited conditions. The concentration of dissolved

1080 organic matter is $C_{\mathrm{DOM}}=5 \mu \mathrm{g}_{\mathrm{C}} / \mathrm{l}$; inorganic nutrients is $C_{N}=4 \mu \mathrm{molN} / \mathrm{l}$

1081 (corresponding to $50 \mu \mathrm{g}_{\mathrm{C}}{ }^{-1}$ ), the light intensity at depth is $C_{L}=2 \mathrm{~W} \mathrm{~m}^{-2}$ and the

1082 concentration of suitable prey organisms is $C_{P}=10 \mu \mathrm{g}_{\mathrm{C}} / \mathrm{l}$. 


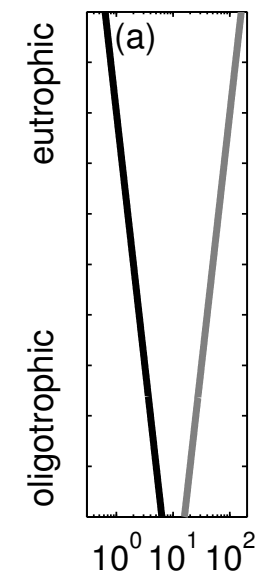

Light $\left(\mathrm{J} \mathrm{day}^{-1} \mathrm{~m}^{-2}\right)$

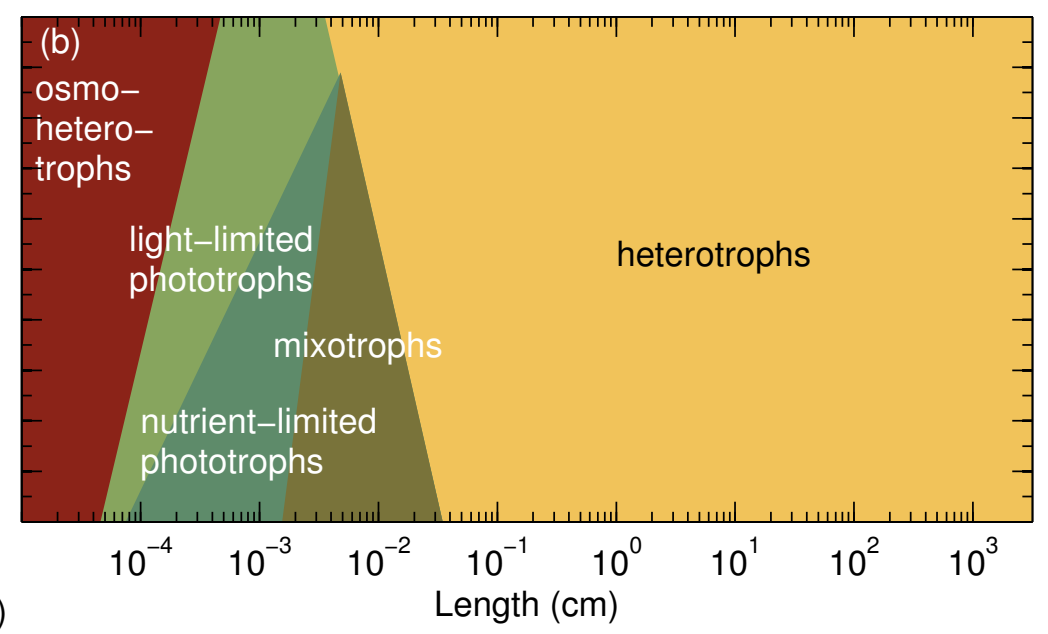

Nutrients $\left(\mu g_{C} / l\right)$

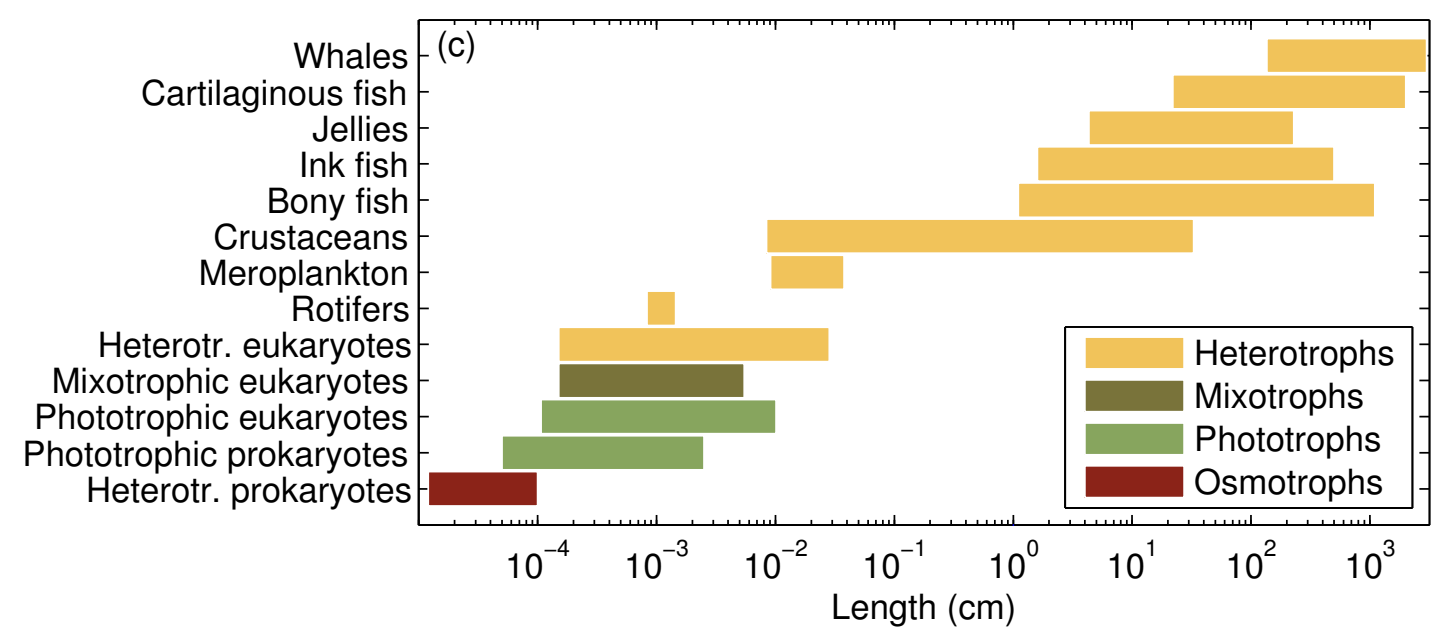

1085 Figure 4. Trophic strategy as a function of size: osmo-heterotrophs (dark red),

1086 phototrophs (green), mixotrophs (army green) and heterotrophs (yellow). (a)

1087 Prescribed variation of nutrient and light conditions from oligotrophic to

1088 eutrophic conditions. (b) Strategy that yields the highest resource encounter rate

1089 as a function of size ( $x$-direction) and resource condition ( $y$-direction) changing

1090 between oligotrophic (high light, low nutrients) to eutrophic conditions (low

1091 light, high nutrients). (c) Trophic strategy of 3020 marine organisms as a

1092 function of length. Ciliates and flagellates have been categorized as phototrophs,

1093 mixotrophs or heterotrophs depending on the trophic strategy for the specific

1094 species (Appendix S2 in Supporting Information). The groupings are whales 
1095 (Cetacea only, i.e. dolphins and whales), cartilaginous fish (Elasmobranchii;

1096 sharks and rays), teleosts (Osteichthyes), Cephalopoda ("ink fish"),

1097 meroplanktonic larvae (i.e. planktonic larvae whose adult stages are benthic),

1098 jellies (Cnidaria, Ctenophora), rotifers (Rotifera), crustaceans (incl. copepods),

1099 and unicellular eukaryotes or prokaryotes.

1100 

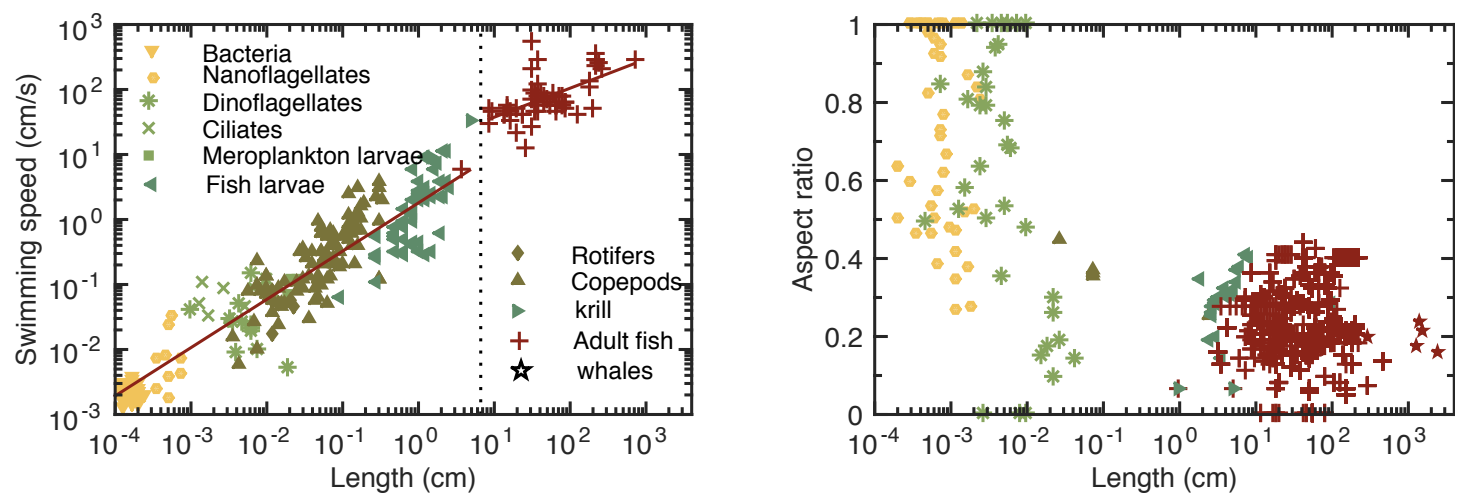

1103 Figure 5. Swimming speeds and body aspect ratio vs. body length. Length is

1104 measured as ESD for planktonic organisms and as longest length for fish larvae,

1105 krill, fish and whales. (a) Swimming speed: data for zooplankton (including fish

1106 larvae) from Kiørboe (2011); fish data (cruising speed) from Sambilay Jr. (1990).

1107 The lines are power law fits (Table 1). The split between the two data sets was

1108 determined as the size that gave the lowest total residual of the fits. The

1109 crossover size at $6.6 \mathrm{~cm}$ corresponds to a Reynolds number around 1000. (b)

1110 Aspect ratio as a function of length for motile marine organisms. Data contain

1111 nanoflagellates and dinoflagellates (Throndsen et al. 2003, Tomas 1997),

1112 copepods (Kiørboe et al. 2010), krill (Watkins \& Brierley 2002), fish larvae (Ara

1113 et al. 2013, Morioka et al. 2013, Moser et al. 1986, Oka \& Higashiji 2012) and

1114 adult fish (Froese \& Pauly 2013). 


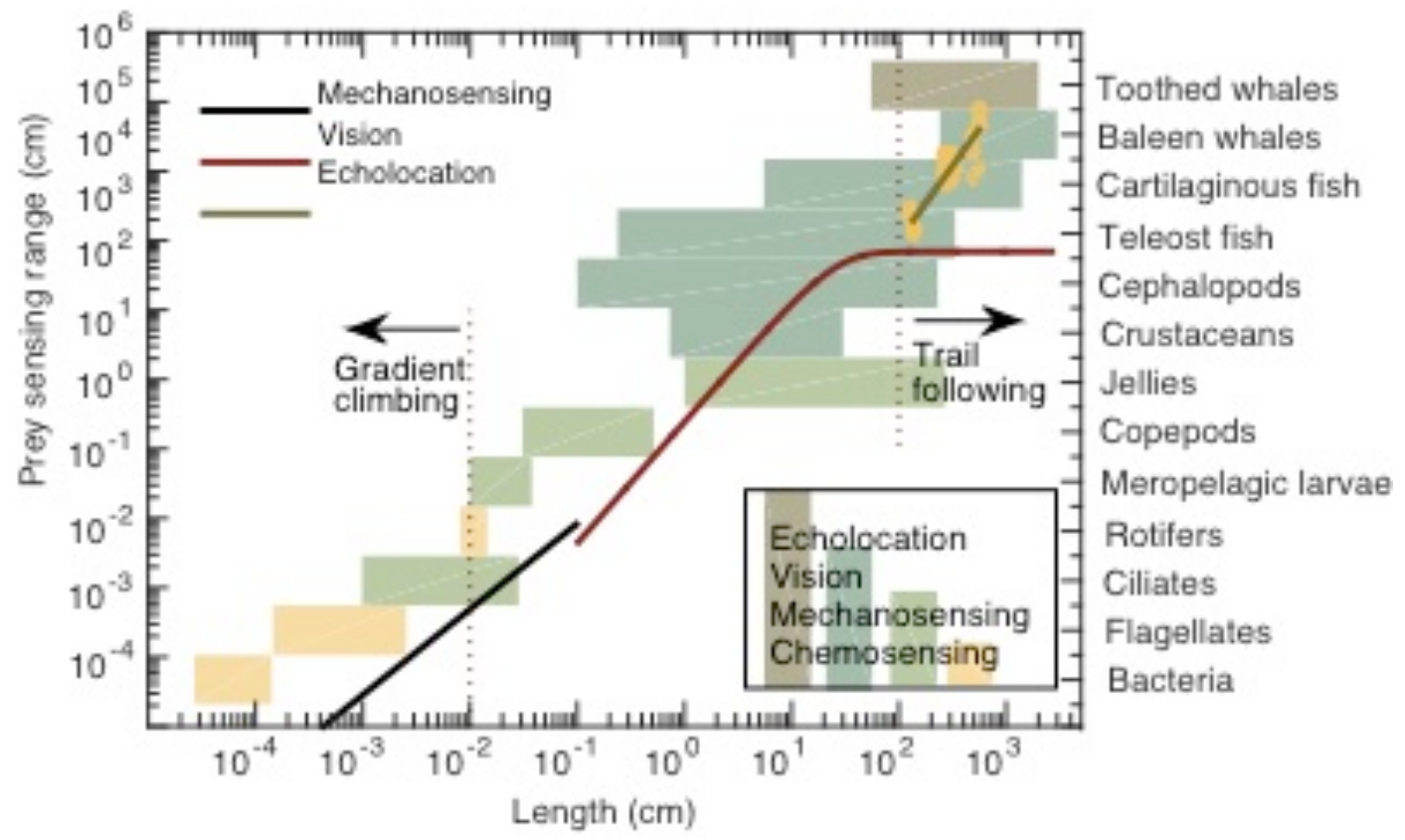

1120 Figure 6. . Senses vs. size. Left axis and lines: Estimated range for sensing a prey a

1121 factor 10 shorter than a predator. (see Sidebar 1 for details). Echolocation range

1122 determined from tank and field measurements of tooth whales of different size

1123 (circles; Table S3.2). The line is fitted with exponent 17/8 (table 1). The vertical

1124 lines are estimates of limits of chemotaxis strategies; see text for details. Right

1125 axis and bars: Senses used for detecting prey grouped according to size and

1126 organismal group (Table S3.1). 


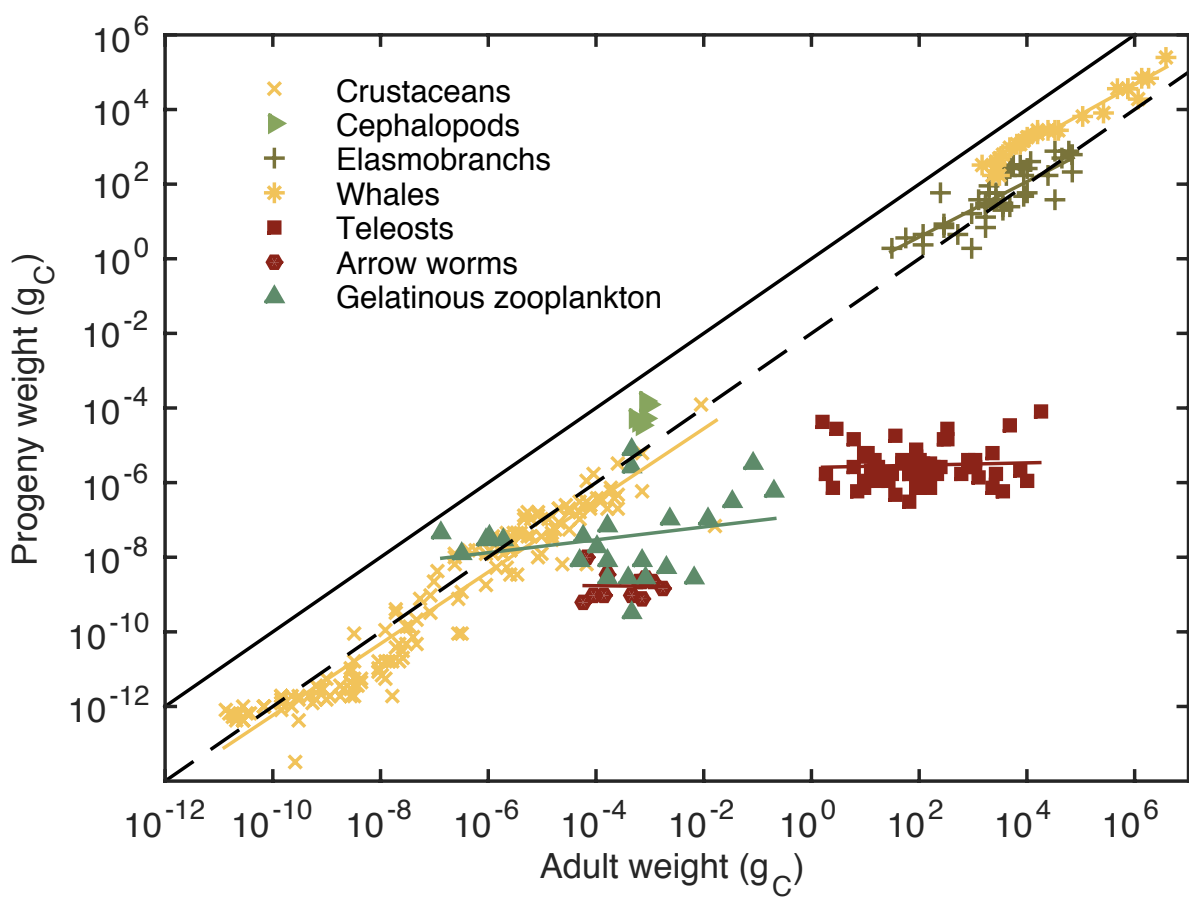

1130 Figure 7. Weights of adults and progeny for metazoans grouped by species of

1131 similar taxonomy. Estimates of mean adult and progeny size were compiled from

1132 the literature, with "adult" defined as individuals that had reached maturity and

1133 "progeny" the smallest size at which offspring are independent of the parent

1134 (Appendix S4). Original data included measures of volume, length, wet weight,

1135 dry weight and carbon dry weight. All were converted to carbon dry weight

1136 using either species-specific or, if unavailable, group-specific conversion factors

1137 from the literature. The solid line is a 1:1 progeny:adult size ratio and the dashed

1138 line is a 1:100 progeny:adult size ratio. Life forms following this line (whales,

1139 cartilaginous fish and crustaceans) follow the "fixed-ratio" strategy, while life

1140 forms with constant progeny size (most notably teleost fish) follow the "small-

1141 eggs" strategy. 